\title{
, \\ Failure Investigation of under Construction Prestressed Concrete Bridge in Chitwan, Nepal
}

\author{
Rabindra Adhikari ${ }^{1,2,3}\left(\mathbb{D}\right.$, , Pratyush Jha ${ }^{2}$, Lalit Bhatt ${ }^{2,3}$, Dipesh Thapa ${ }^{1}$, Davide Forcellini ${ }^{4, *(D)}$ and \\ Dipendra Gautam $1,2,5,6$ (iD
}

1 Department of Civil Engineering, Cosmos College of Management and Technology, Lalitpur 44600, Nepal; rabindraadhikari@cosmoscollege.edu.np (R.A.); 130593dipesh@cosmoscollege.edu.np (D.T.); dipendra01@tcioe.edu.np (D.G.)

2 Interdisciplinary Research Institute for Sustainability, IRIS, Kathmandu 44601, Nepal; pratyush@ngen.com.np (P.J.); 076msste010.lalit@pcampus.edu.np (L.B.)

3 Department of Civil Engineering, Institute of Engineering, Pulchowk Campus, Lalitpur 44600, Nepal

4 Department of Civil and Environmental Engineering, University of Auckland, Auckland 1010, New Zealand

5 Department of Civil Engineering, Institute of Engineering, Thapathali Campus, Kathmandu 44601, Nepal

6 Nepal Academy of Science and Technology, Lalitpur 44600, Nepal

* Correspondence: dfor295@aucklanduni.ac.nz

check for

updates

Citation: Adhikari, R.; Jha, P.; Bhatt,

L.; Thapa, D.; Forcellini, D.; Gautam,

D. Failure Investigation of under

Construction Prestressed Concrete

Bridge in Chitwan, Nepal.

Infrastructures 2022, 7, 14.

https: / /doi.org/10.3390/

infrastructures7020014

Academic Editor: Luís

Oliveira Santos

Received: 12 December 2021

Accepted: 22 January 2022

Published: 24 January 2022

Publisher's Note: MDPI stays neutral with regard to jurisdictional claims in published maps and institutional affiliations.

Copyright: () 2022 by the authors Licensee MDPI, Basel, Switzerland. This article is an open access article distributed under the terms and conditions of the Creative Commons Attribution (CC BY) license (https:// creativecommons.org/licenses/by/ $4.0 /)$.

\begin{abstract}
On 6 April 2021, a 200 m-long under-construction prestressed concrete bridge failed in the Chitwan District in central Nepal. Two of the four bridge spans collapsed without any notable evidence of dynamic force application. Under-construction bridge failures are sometimes reported and can have a significant impact on the future construction adjustments. Thus, a detailed study of failure mechanisms will be insightful for the structural engineering community. Aiming to document the failure modes and exemplify lessons for improvement, this paper reports the detailed component level failure mechanisms of the bridge using visual inspection, site measurements, finite element modeling, and some forms of non-destructive testing. The chronological failure mechanisms are presented based on the field evidence and juxtaposed with the results of analytical modeling. The sum of findings highlights that the dead load failure, triggered by the settlement of falseworks, is the most critically governing factor that initiated and aggravated the damage scenario.
\end{abstract}

Keywords: prestressed concrete bridge; falsework; forensic analysis; construction failure

\section{Background}

Bridges are critical infrastructures and the unrestricted operability of bridges must be assured, even after their exposure to severe dynamic forces, such as earthquakes, floods, and tsunamis, etc. Many studies exist worldwide to assess the performance of bridges under natural hazard events (e.g., [1-5]); however, limited works have been reported so far regarding during-construction failures of bridges. For example, Peng et al. [4] reported the forensic damage analysis of a collapsed ramp bridge in Hangzhou, China. Using observations, descriptions from local witnesses, and videographic evidence combined with numerical analyses, they concluded that the addition of a sidewalk and the replacement of a symmetric section of the bridge girder by an asymmetric section were the main causes of the collapse. The bridge damage was aggravated by a minor earthquake as well, which resulted in greater lateral loading. The authors also recommended the use of pre- and post-event evidence to dissect the overturning collapse of box-girder bridges. Similarly, Scattarreggia et al. [6] analyzed the Caprigliola bridge collapse in Italy using field observations and the results of applied element modeling. They shed light on the damage mechanisms, assessing the most likely damage mechanism that intersected between observed and modeled scenarios. They further recommended intermixing regular monitoring and inspection as well as reliable structural modeling to outline the impending severities in bridge structures. 
Moreover, Clemente [7] reported on the Polcevera Viaduct collapse in Italy, highlighting that good design is not enough to assure the functionality of bridges throughout service life. The author highlights the importance of the monitoring and evaluation of existing bridges so as to downscale the likelihood of severity in terms of damage/collapse. The Polcevera Viaduct collapsed due to the lack of cable-stay support, which resulted in the fracture of the first cable stay [7]. The collapse of the Florida International University pedestrian bridge is extensively studied by considering forensic analysis [1,8]. Cao et al. [1] concluded that the collapse of the Miami pedestrian bridge was attributed to an exceedance of retensioning force over the joint resistance, leading to joint slide, and the subsequent cycles of sliding led to the collapse.

Prestressed concrete bridges are widely studied considering various performance objectives. For example, Meng et al. [9] studied the long-term deflection of prestressed concrete bridges under heavy vehicle loading. Yang et al. [10] performed an experimental investigation to identify the behavior of prestressed bridges under sustained loading and corrosion. They concluded that corrosion is a more promising factor influencing tensile strength. Bonopera and Chang [11] performed laboratory testing in a simply supported prestressed concrete beam for 9.5 months to estimate the residual prestress force. Although many researchers perform various types of analyses, attention regarding the global performance of prestressed and other types of bridges is still very crucial. Recent advances in terms of dynamic identification can be very crucial to understand and depict the behavior of bridges under dynamic loading [12]. Given the severity of multiple independent and natural hazards that directly affect the bridge structures, long-term resilience and loss assessments are crucial for any type of highway bridge, as highlighted by Li et al. [13]. Apart from long-resilience and loss assessments, vulnerability assessments of highway bridges under various dynamic loading are inevitably a prerequisite to assure the target performance level, especially after a major natural hazard. Thus, several studies have reported the vulnerabilities of highway bridges under dynamics excitations (e.g., [14-16]). It should be reiterated that bridges are an important link for communities and their failure needs to be considered with advanced methodologies, such as those proposed by [17-20]. Moreover, a compliance-based methodology, such as that reported by study [21], for the estimation of the seismic collapse risk of existing buildings and bridges could also be remarkable.

As most of the studies reported so far consider the failure analysis of a bridge in operation, there lies a clear gap of knowledge regarding the collapse of under-construction bridges. Due to the lack of proper construction planning and the thorough execution of the agreed construction sequence and system, alterations may occur beyond the design consideration, which may lead to the collapse of a bridge. To build up the knowledge regarding the collapse of under-construction bridges, the present study uses a forensic analysis to assess a bridge collapse incident that occurred in April 2021 in Nepal. The aim of this paper is to derive the causes of the collapse of the Thimura bridge using visual observations, forensic analysis, and by analyzing a global finite element (FE) model of the bridge. The outcomes are herein discussed to derive some lessons that could be insightful for other regions to prevent similar collapses.

\section{Thimura Prestressed Bridge Collapse}

On 6 April 2021, two spans of the under construction Thimura-Devghat bridge that connects Thimura of Chitwan District and Devghat of Tanahun District in central Nepal collapsed. The bridge was $200 \mathrm{~m}$ long (excluding approach slabs) with a mixed reinforced prestressed concrete and steel truss superstructure. The bridge was designed to be composed of four spans, starting from left side (Thimura of Chitwan District); first, second, and fourth spans were designed to be simply supported as prestressed concrete spans of $40 \mathrm{~m}$ each. The third span was designed to be a simply supported steel truss of an $80 \mathrm{~m}$ span. The bridge was designed in November 2015 and was customized for minor modifications until February 2016 when the final structural design was approved. It was targeted to be in 
operation by June 2021. The bridge has abutments of $12.14 \mathrm{~m}$ in height on both banks, and three piers of diameters $13.735 \mathrm{~m}, 15.535 \mathrm{~m}$, and $15.535 \mathrm{~m}$, respectively. The diameter of the pier on the leftmost side is $2.8 \mathrm{~m}$ and the rest of the piers have the diameter of $3.4 \mathrm{~m}$. The piers were constructed in 2018. In the design, M45 concrete was used. A schematic drawing of the bridge is presented in Figure 1.

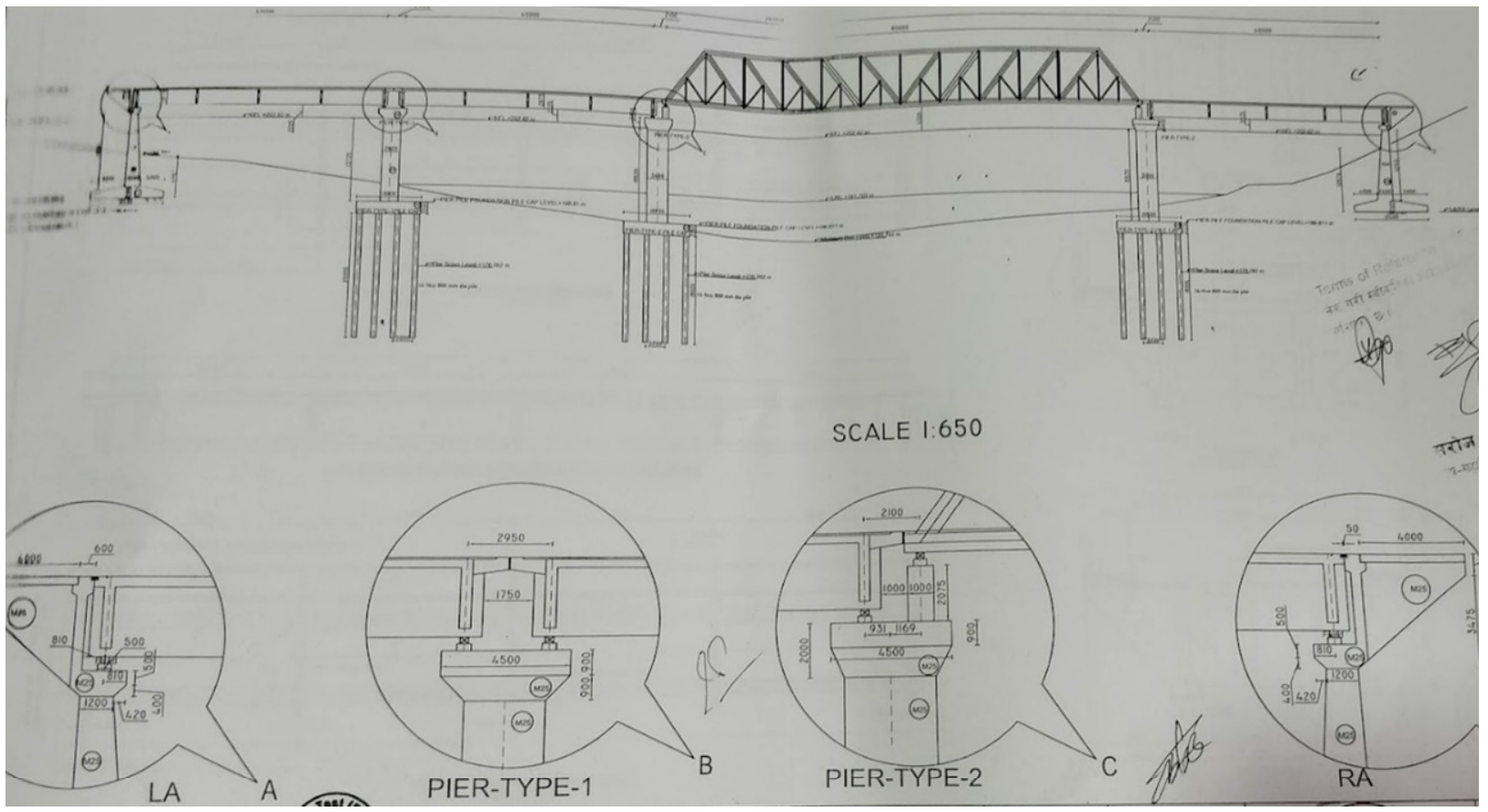

Figure 1. Schematic details of the bridge (generously shared by Department of Roads, Chitwan Division, Nepal).

The first and fourth spans were structurally completed, and the second and third spans were undern construction, when the partial collapse event occurred (Figure 2). The two spans located towards Thimura (left bank) collapsed in the early morning (4:30 am local time) of 6 April 2021. The collapse would have led to a loss of human life or injury had it occurred during working hours.

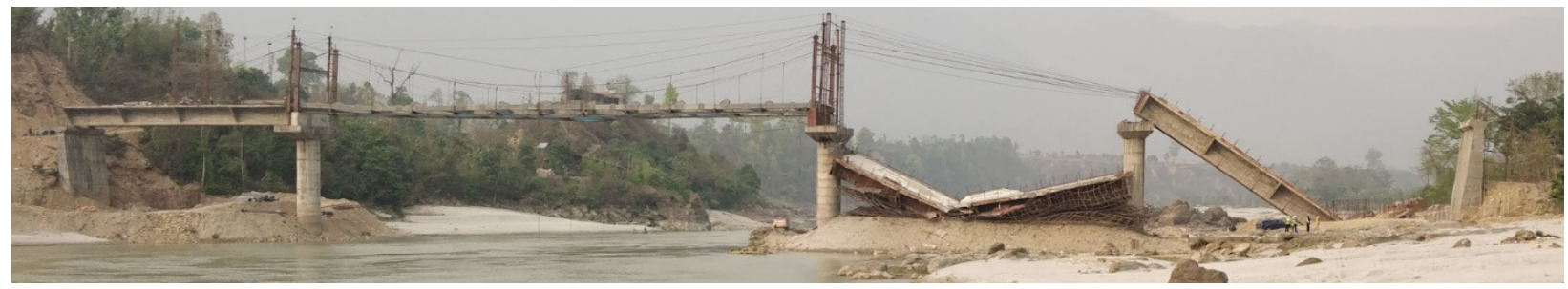

Figure 2. Thimura prestressed bridge with two collapsed spans.

\section{Overview of Bridge Construction System}

The abutments were constructed with shallow foundations, while pile foundation was provided for piers due to the soil condition. The substructures were constructed following the standard guidelines suggested by the Government of Nepal regulations. For the construction of the prestressed concrete span, concrete should achieve its design strength before prestressing. Hence, concrete was cast by embedding hollow ducts so as to insert prestressing cables, and curing was done to guarantee sufficient hardening before prestressing. Concrete casting was done using steel formworks and steel props (falseworks) supported over the temporary embankment that comprised of loose sand and gravel piled 
up from the same site, in order to reduce the height of the falseworks. Concreting of a reinforced concrete (RC) span was completed in two days. On the first day, about an $80 \%$ depth of the beam was concreted, and on the second day, the remaining portion of beam and slab was completed. Afterwards, ponding was done over the slab for about 28 days. The same approach was adopted for concreting in all three spans. Because of the water volume and the high level of water in the river, it was extremely difficult to divert the water to provide staging for the erection of the steel on the third span. Hence, an alternate approach was used to erect the steel span. Steel towers were constructed, as shown in Figure 3, to support multiple cables to transport the steel sections.

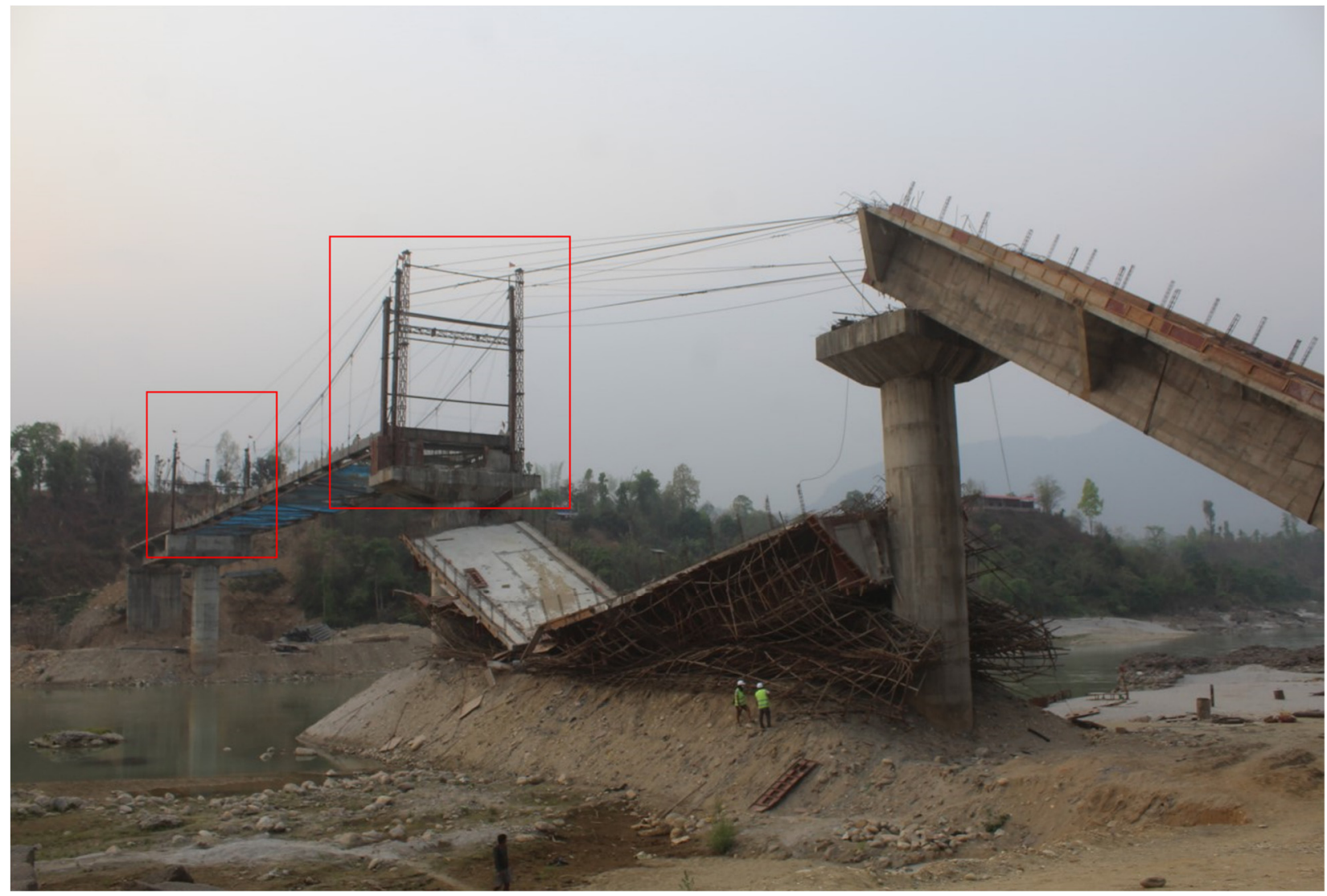

Figure 3. Steel towers constructed on pedestal.

\section{Forensic Damage Assessment}

The first and second concrete spans fell off the piers and were destroyed (Figure 4). The first span fell off the abutment, meanwhile the slab still stood leaning on the first pier, with a total cantilevered portion of $\sim 1 \mathrm{~m}$ (Figure 4 ). The second span fell off both piers with a fracture nearby the mid-span (Figure 5). Damage to individual components is presented in the following section.

\subsection{Damage to Beams}

The first span fell off the first abutment that was governed by the settlement of the foundation soil. Thereafter, the beam hit the ground causing intense damage to approximately $25 \%$ of the length of the beam/slab in the first span. The remaining portion of the span only had some cracks, without reinforcement exposure. Horizontal shear failure of the beam concrete was observed in Span-1, as shown in Figure 6, which should have been initiated after the impact on the ground due to the occurrence of large shear stress. Interestingly, the shearing location exactly matched with the construction joint (interface of first day and second day concreting), as shown in Figure 7. Distinct flexure crack and 
yielding were identified in the beams of Span-2. The prestressing cables were exposed due to flexure cracking, and the falling of the span caused breakage. Figure 8 shows a typical damaged section of the beam of Span-2. The end cross beams of Span-2 slid on the pier surfaces, thus sustaining heavy damage. As the bridge span fell down, the span was not housed within the available space between the piers. Therefore, it slid over the pier surface, the central portion of beam being the lowest point that got fractured.

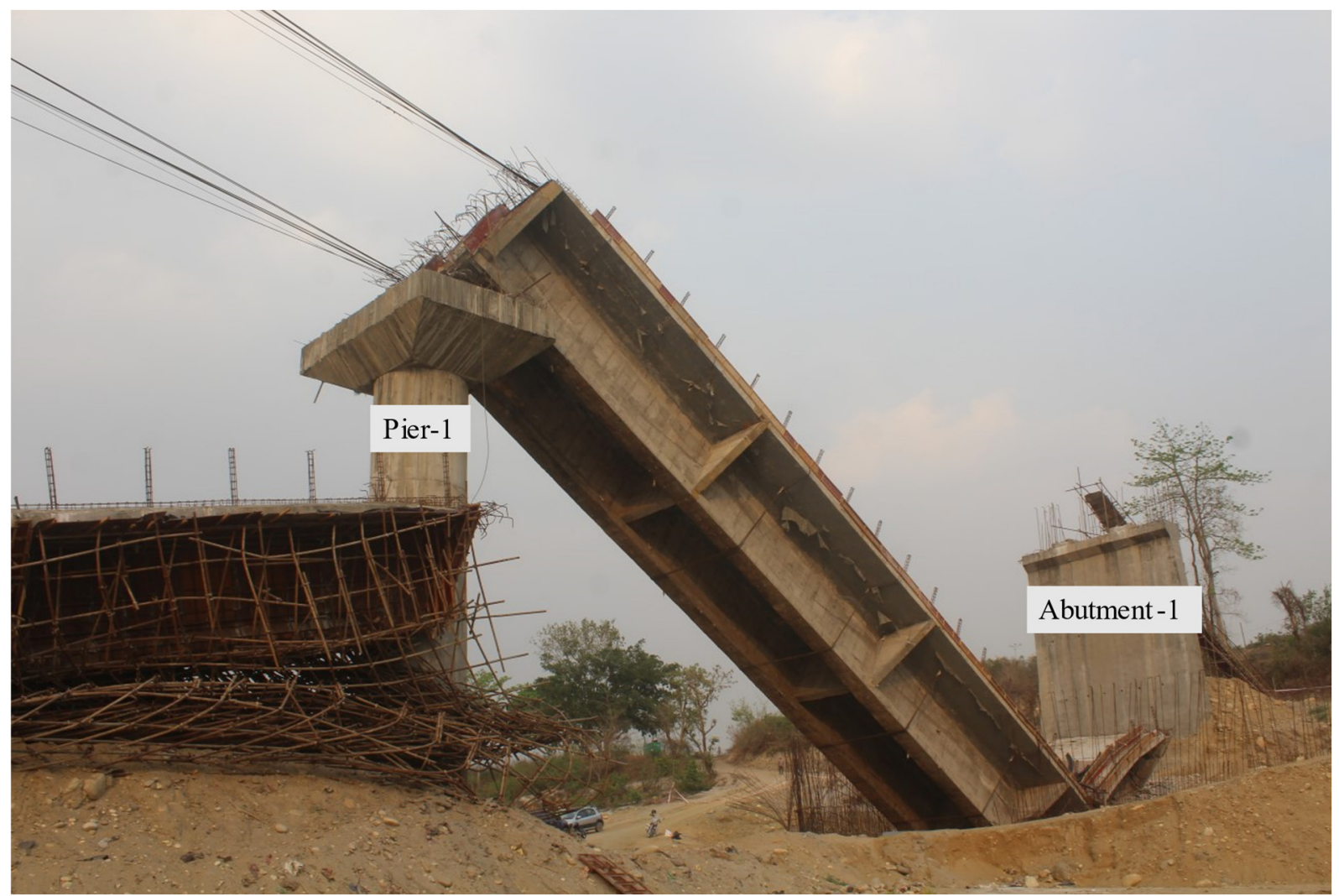

Figure 4. Collapsed first span of the bridge.

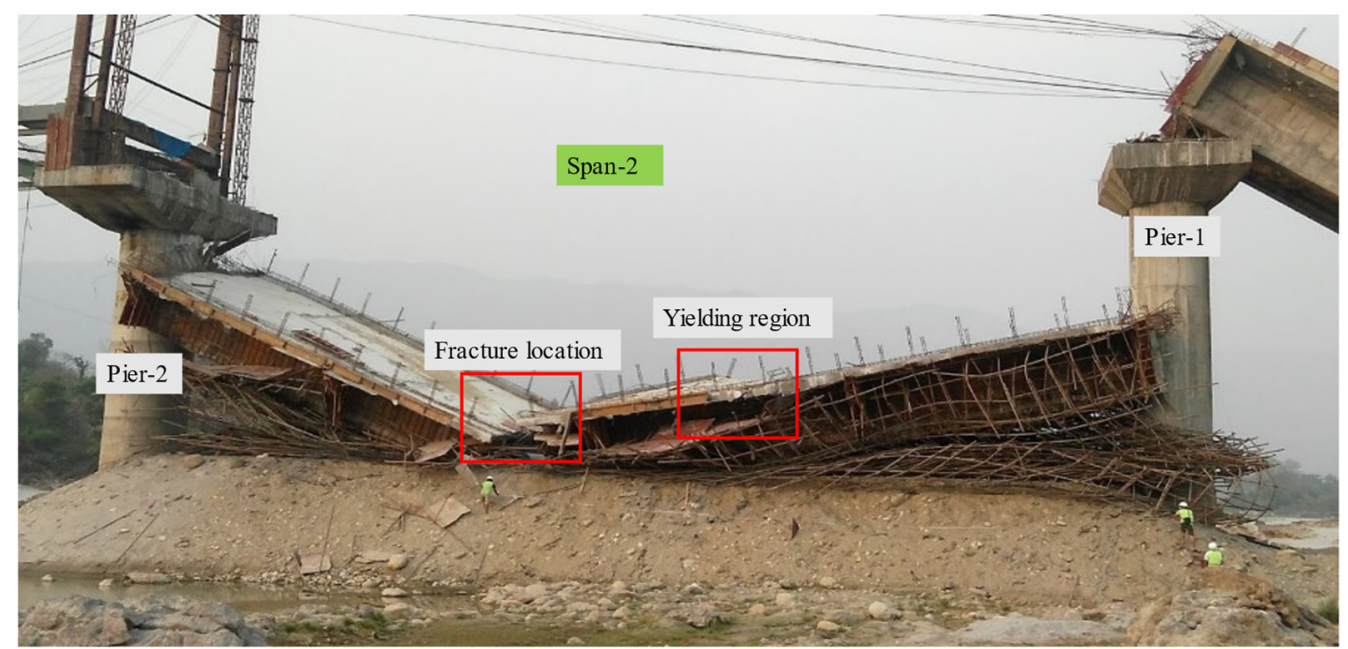

Figure 5. Destroyed second span of the bridge. The damaged props can be observed rested above loose sand and gravel. 


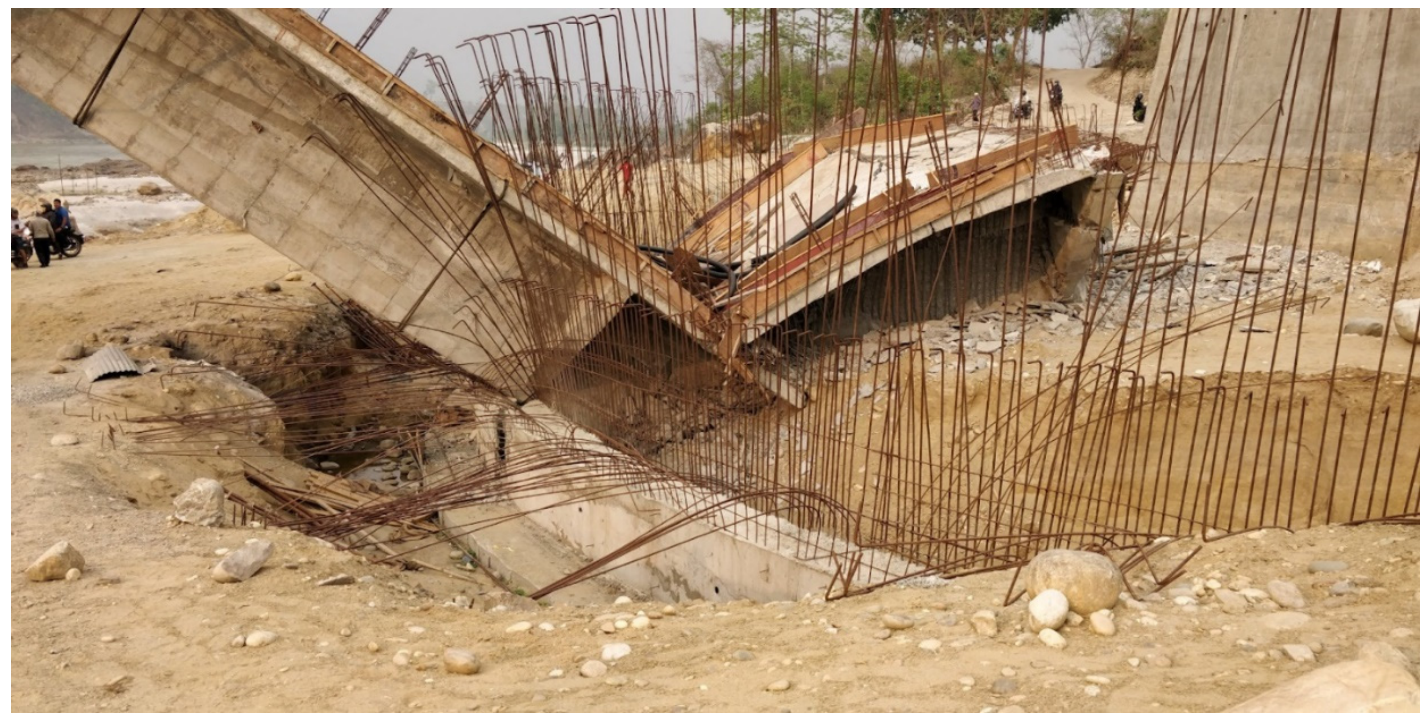

Figure 6. Collapsed Span-1 of the bridge.

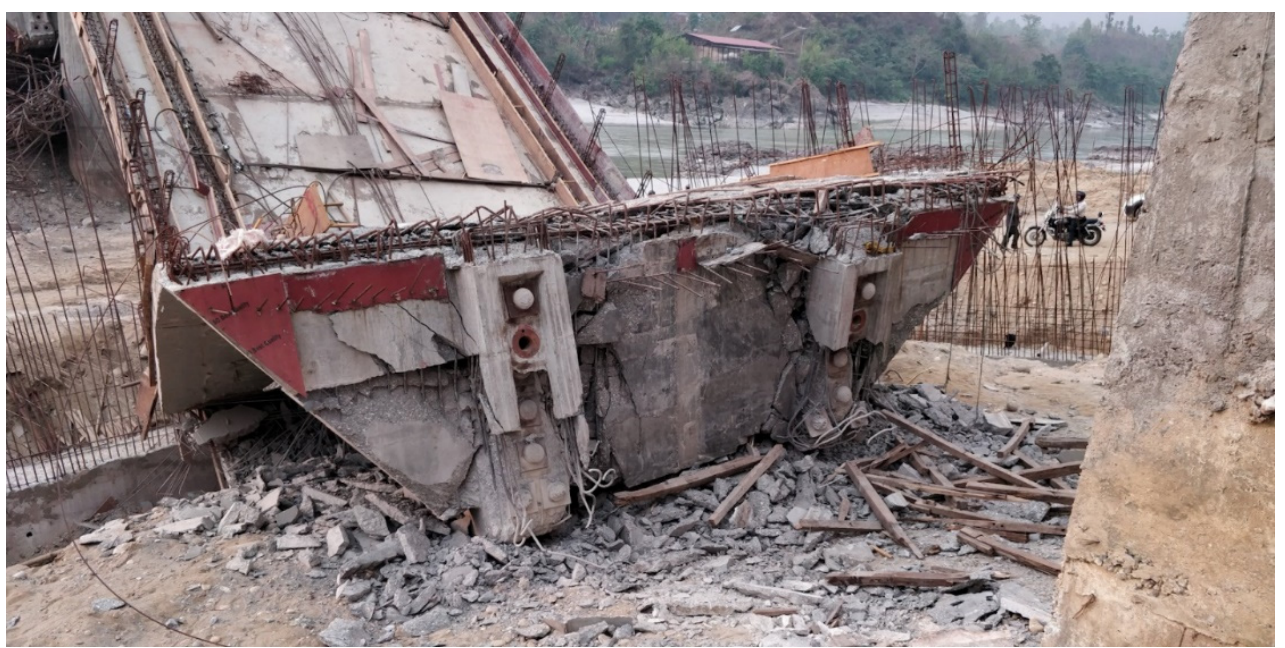

Figure 7. Horizontal shear failure at construction-joint level as the lower part of the beam that included four prestressing ducts slid inwards.

\subsection{Damage to Slab}

Span-1 and Span-2 separated from the piers/abutment and fell down. The slab was completely fractured together with the beam in both spans. In Span-1, there was some overlap of the slab (Figure 9) after fracture. The Span-1 deck was used to hold the temporary suspension cables from Span-3 for its erection. The deck was slightly shifted towards Span3 and fell off from the Abutment- 1 side only, while the Pier-1 side stayed above the pier. Apart from the complete fracture of the slab in Span-2 (Figure 9), there were several notable cracks on various parts of the slab (Figure 10), most likely due to the impact after falling. Importantly, several flexural cracks were observed on the slab on both sides of the slab separation in Span-2. While many bars of slab were found to be broken due to necking, many others were found at its end, indicating that the fractured section was the lap zone for quite a lot of bars (Figures 11 and 12). 


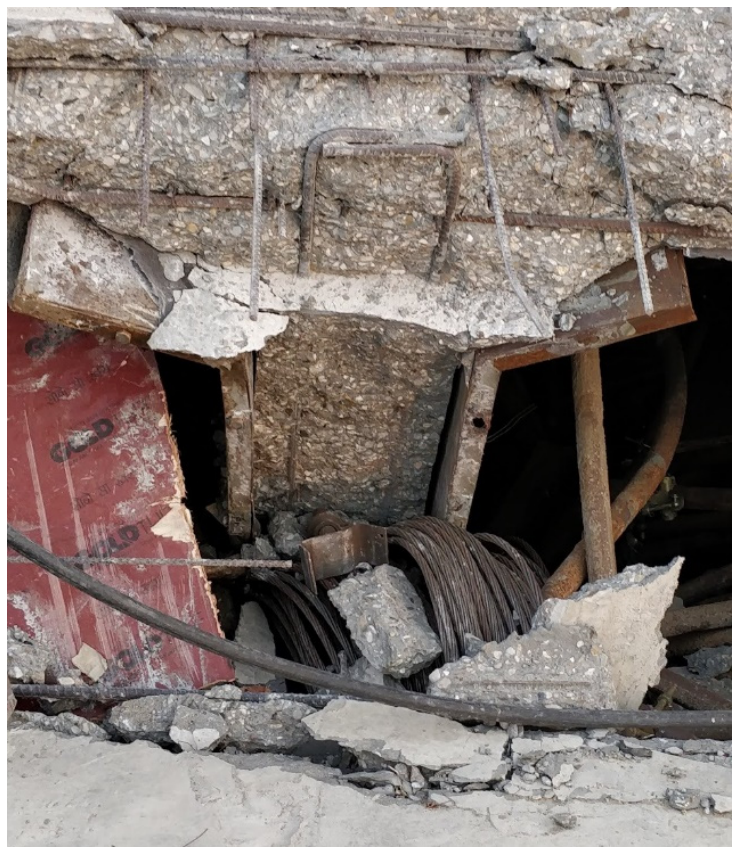

Figure 8. L-bar of fractured beam, anchorage failure of some slab rebar, bearing failure of formwork around bolting holes, and prestressing cables pulled out to significant length and bent.

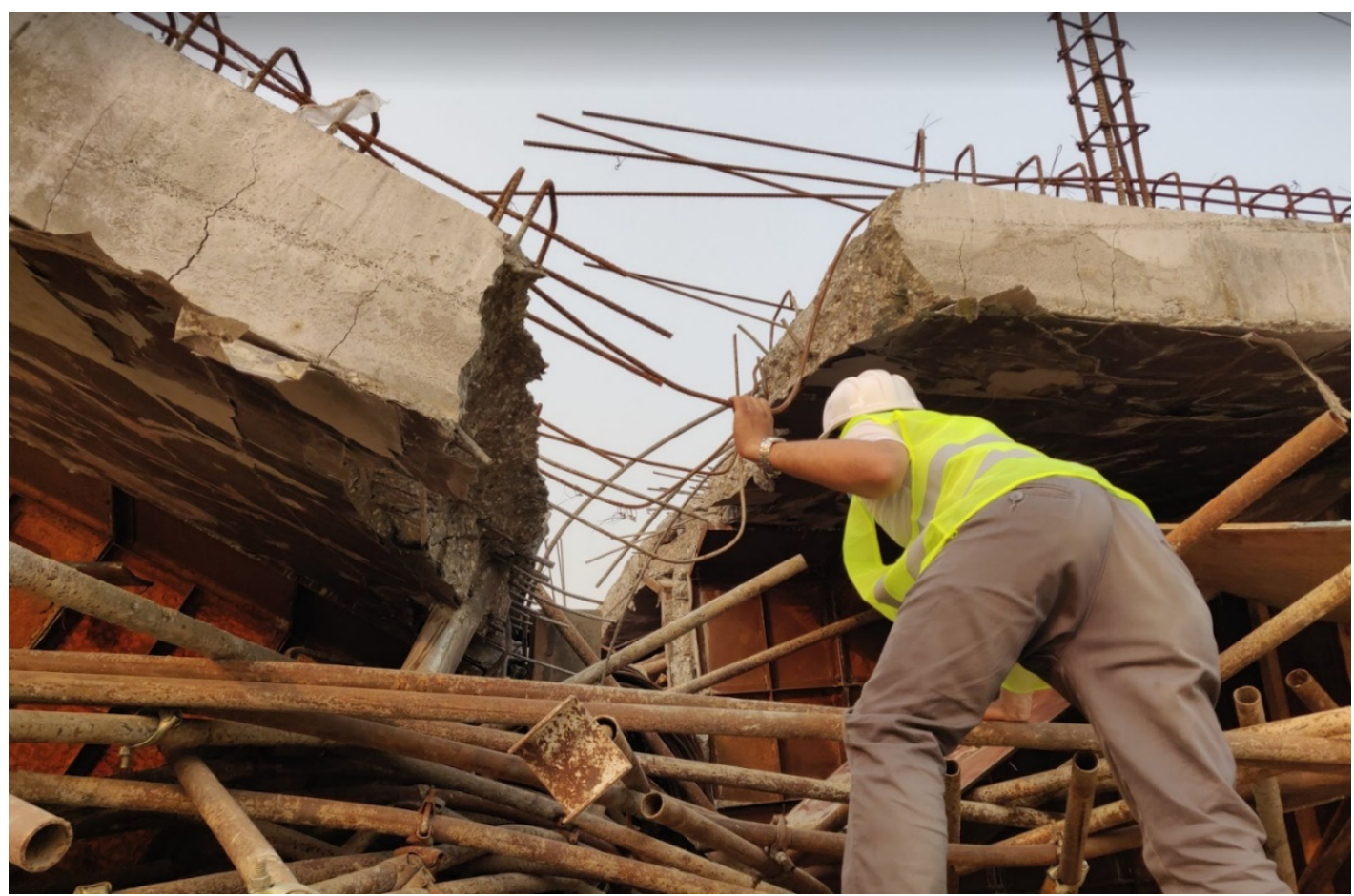

Figure 9. Fracture observed in slab of Span-2, including several flexural cracks near both sides of the main fracture region. 


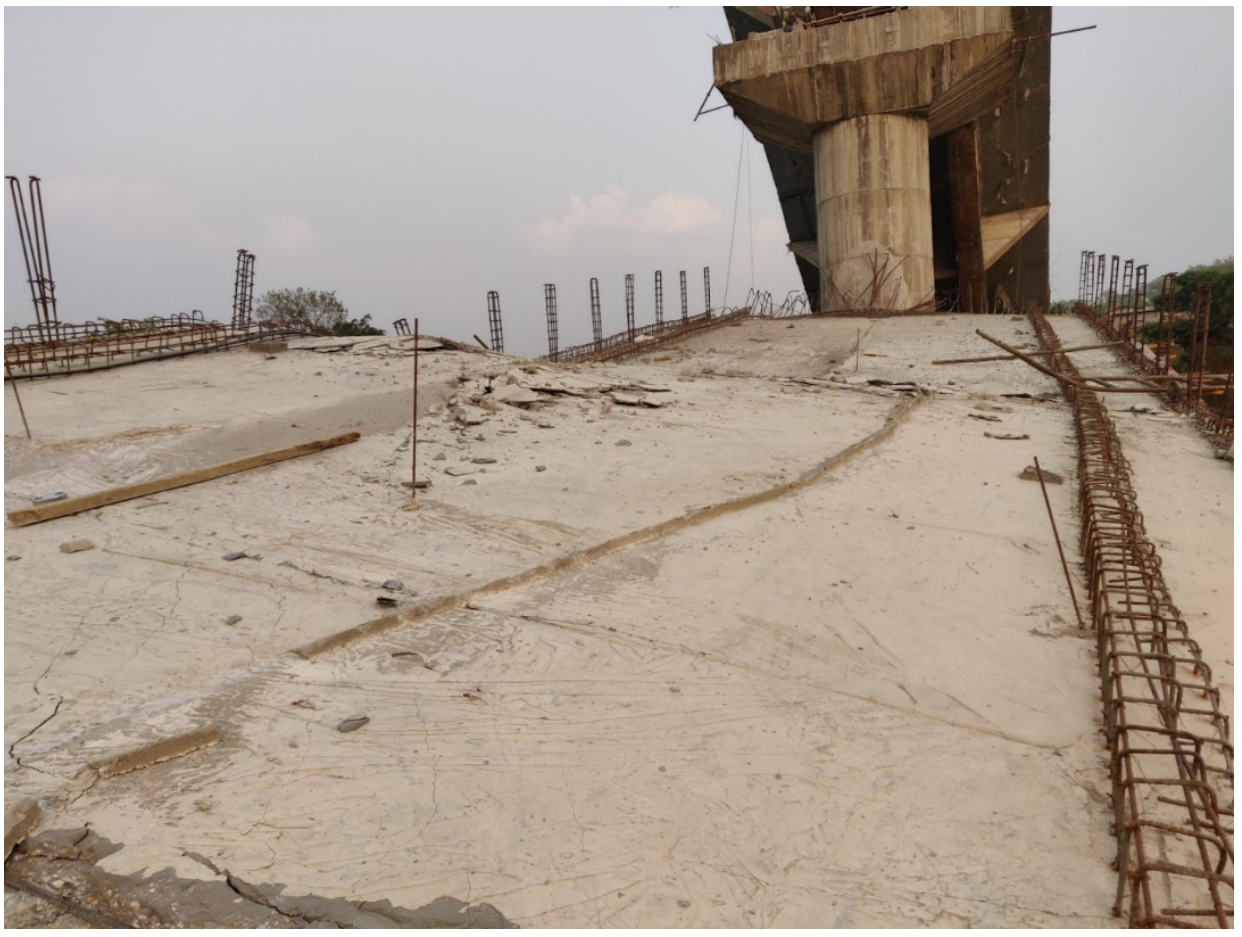

Figure 10. Cracks observed along the slab surface of Span-2.

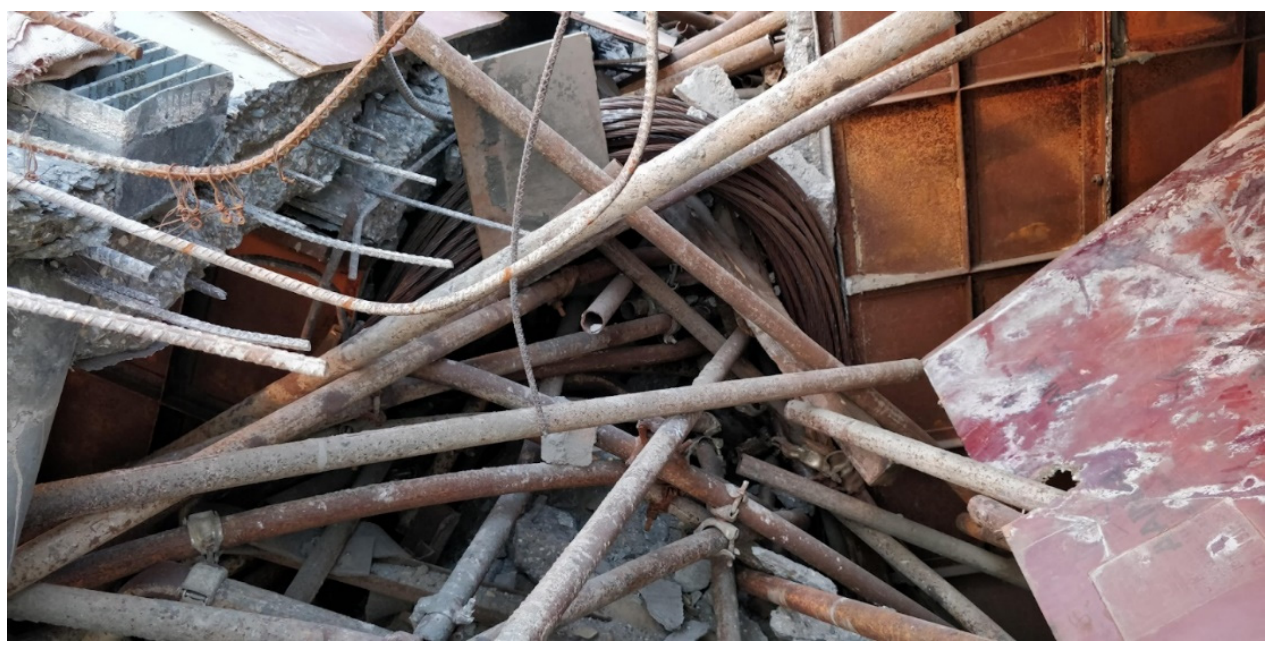

Figure 11. Several bars in the slab of Span-2 can be observed being pulled out and show up in pairs, indicating the significant lapping region of the slab; the prestressing cables were also pulled out to significant length during collapse.

\subsection{Damage to Bearings}

Bearing damage was attributed mostly to the horizontal movement of girders. A pot bearing system was used in the bridge, as shown in Figure 13. Bearing damage was observed in Abutment-1, Pier-1, and Pier-2, as shown in Figure 14, Figure 15, Figure 16, and Figure 17, respectively. 


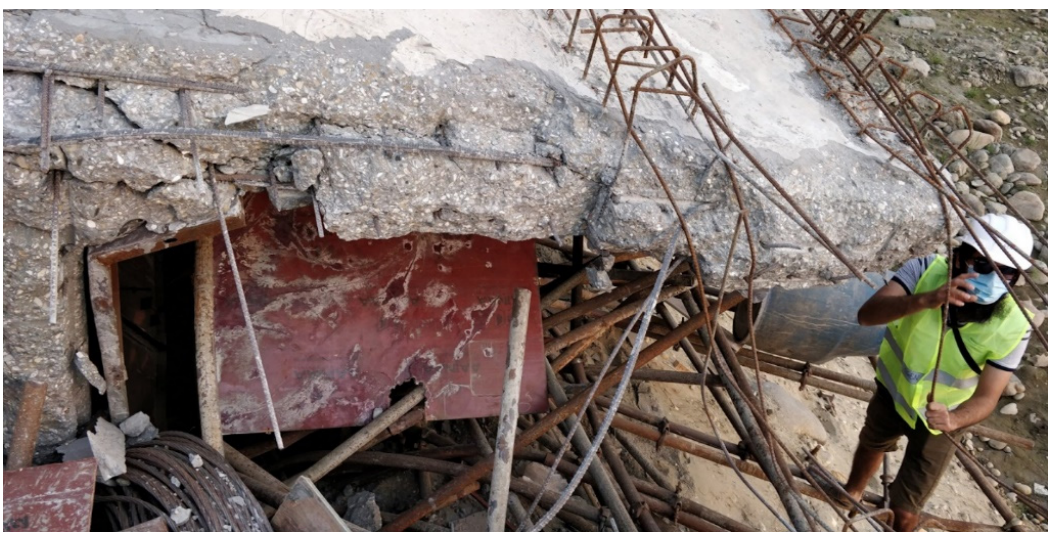

Figure 12. Pulled-out holes in slab in the fractured location.

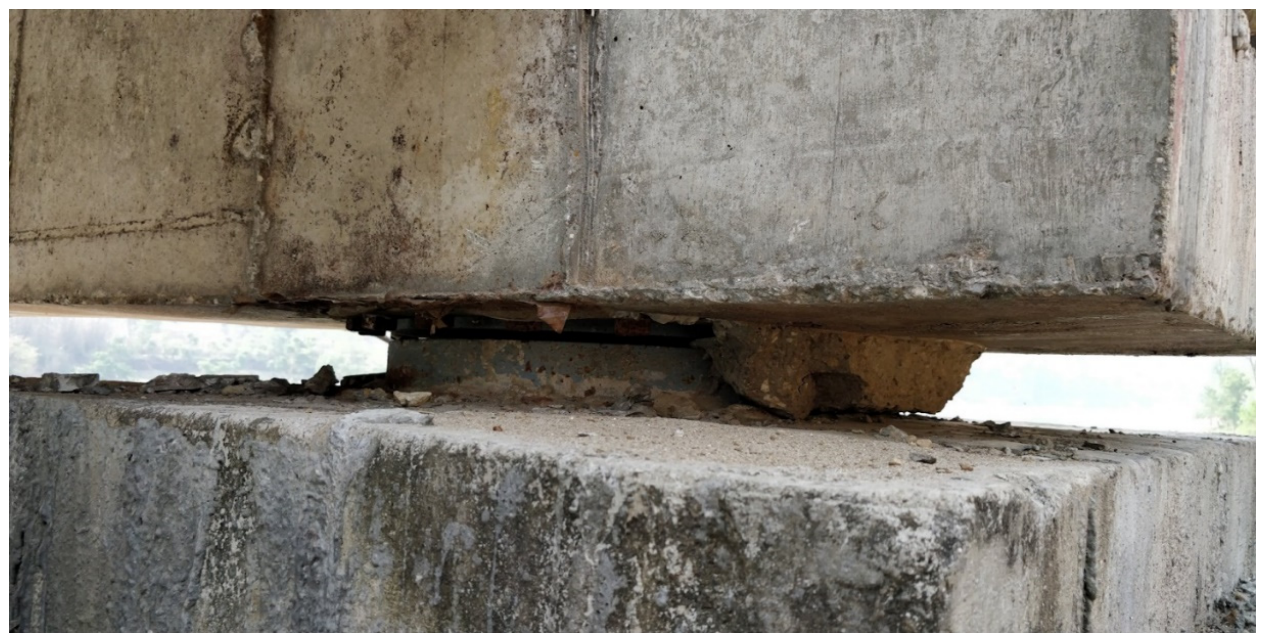

Figure 13. Pot bearing system above Abutment-2 (Undamaged).

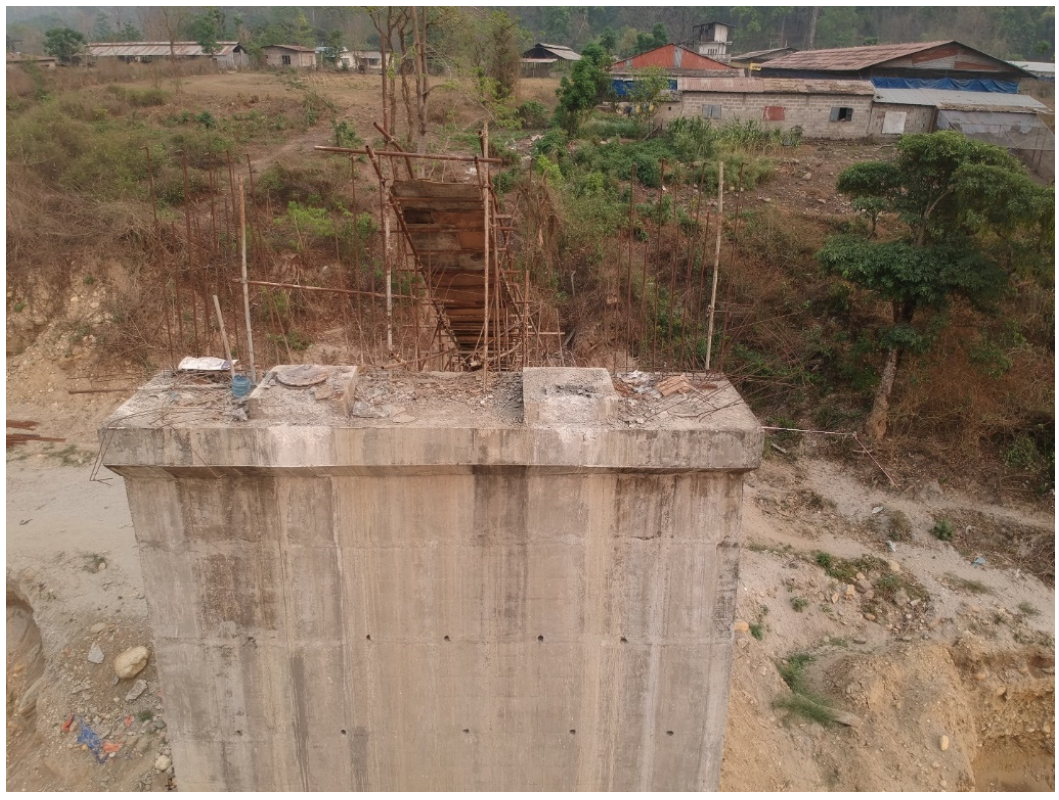

Figure 14. Bearing damage in Abutment-1 due to slippage of the slab before falling. 


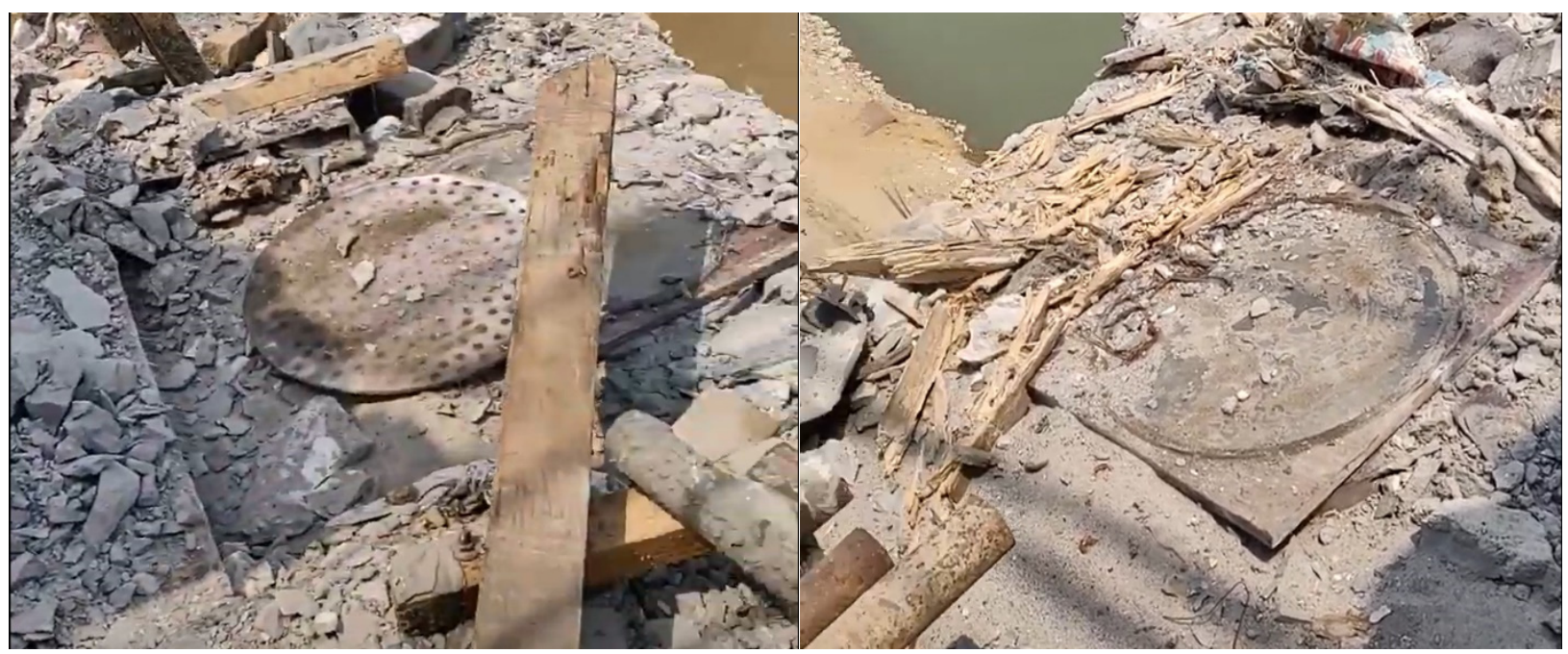

Figure 15. Damaged bearing above Pier-1, span-2 side (downstream and upstream side).

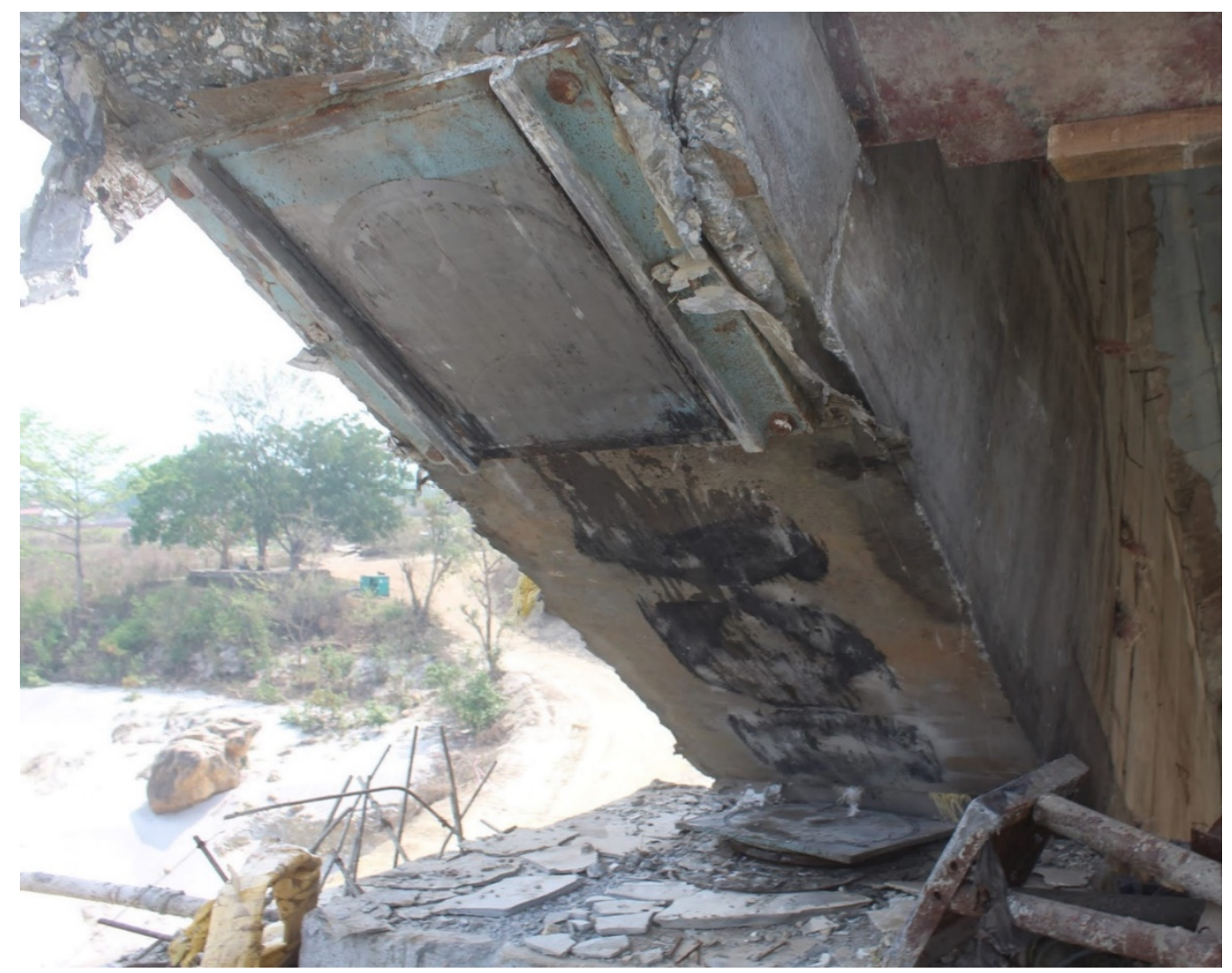

Figure 16. Span-1 deck (over Pier-1) that slid about $1 \mathrm{~m}$ towards Pier-1 indicating drag of deck (shown by bearing mark under the beam surface) and damage of bearing. 


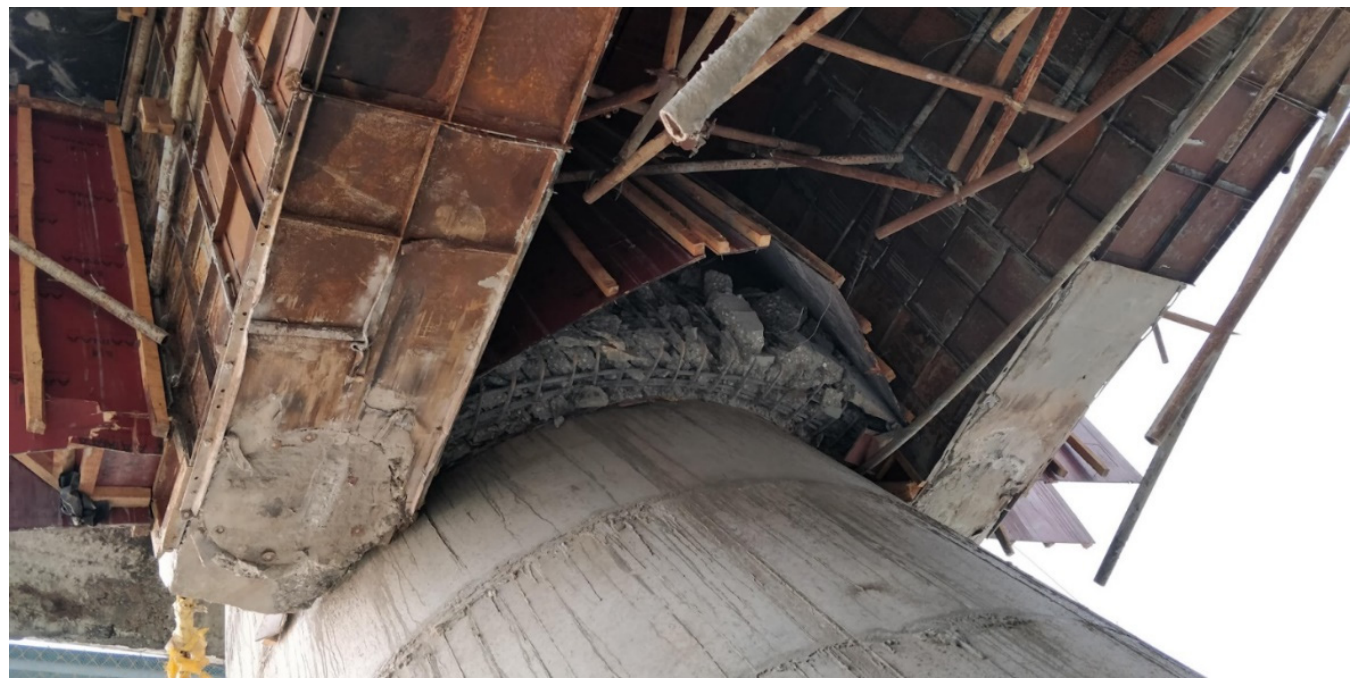

Figure 17. Bearing indentation in the beam with sheared bolts lodged (Pier-2).

\subsection{Damage to Pier}

Some portions of piers were damaged due to the sliding of the deck of Span-2 (Figure 18) during falling. Similarly, the pier cap of Pier-1 (RC bearing pad) was slightly damaged by the collapsed slab of Span-1 (Figure 19). Pier-1 was pushed due to the collapse of the Span-1 and Span-2 in opposite directions, as shown in Figure 20. Meanwhile, Pier-2 was solely pushed by the collapsed slab portion of Span-2. A horizontal crack, as shown in Figure 21, was observed in Pier-1 at a $2.5 \mathrm{~m}$ height from the ground level. It is due to the subsequent interaction between Span-1 and the collapsed slab of Span-2.

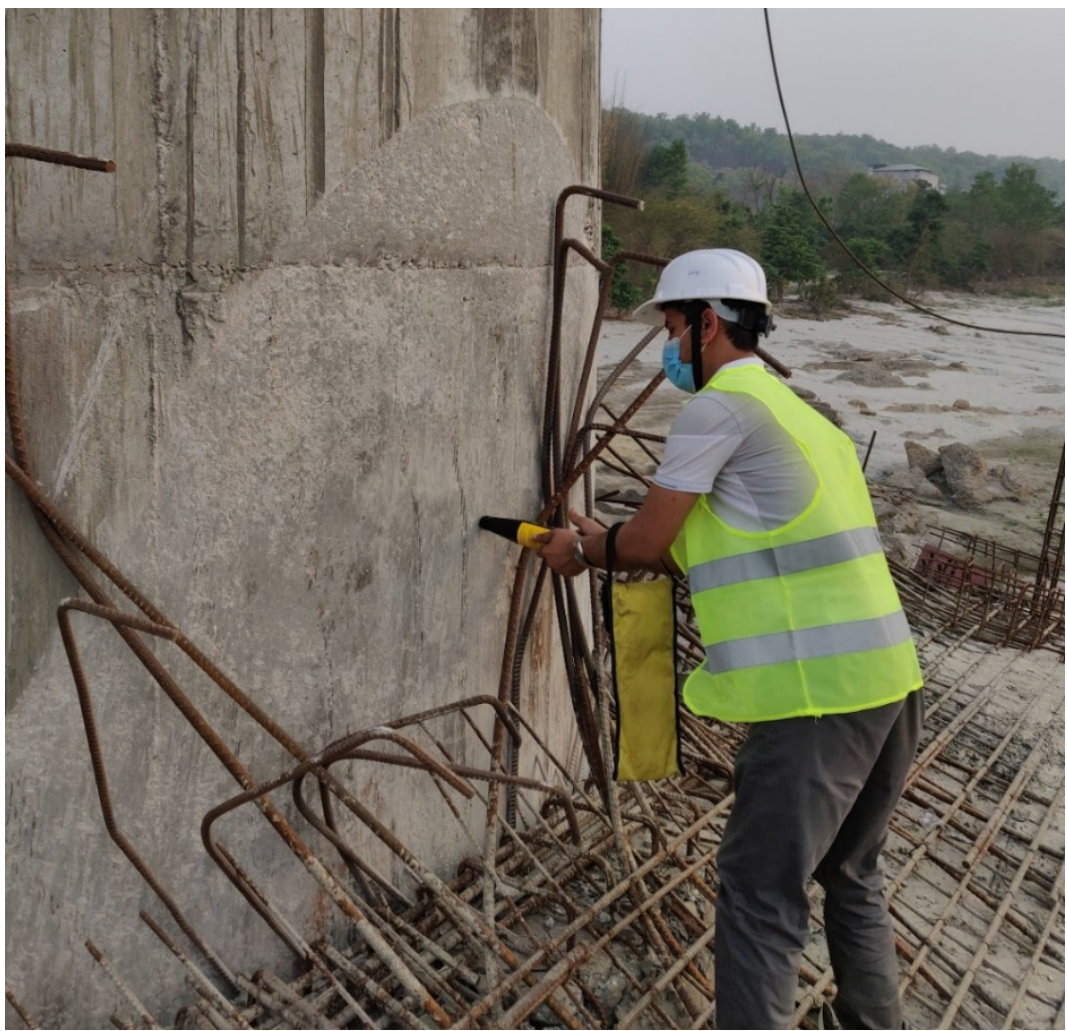

Figure 18. Damage to Pier-1 by end cross beam of Span-2 during collapse. 


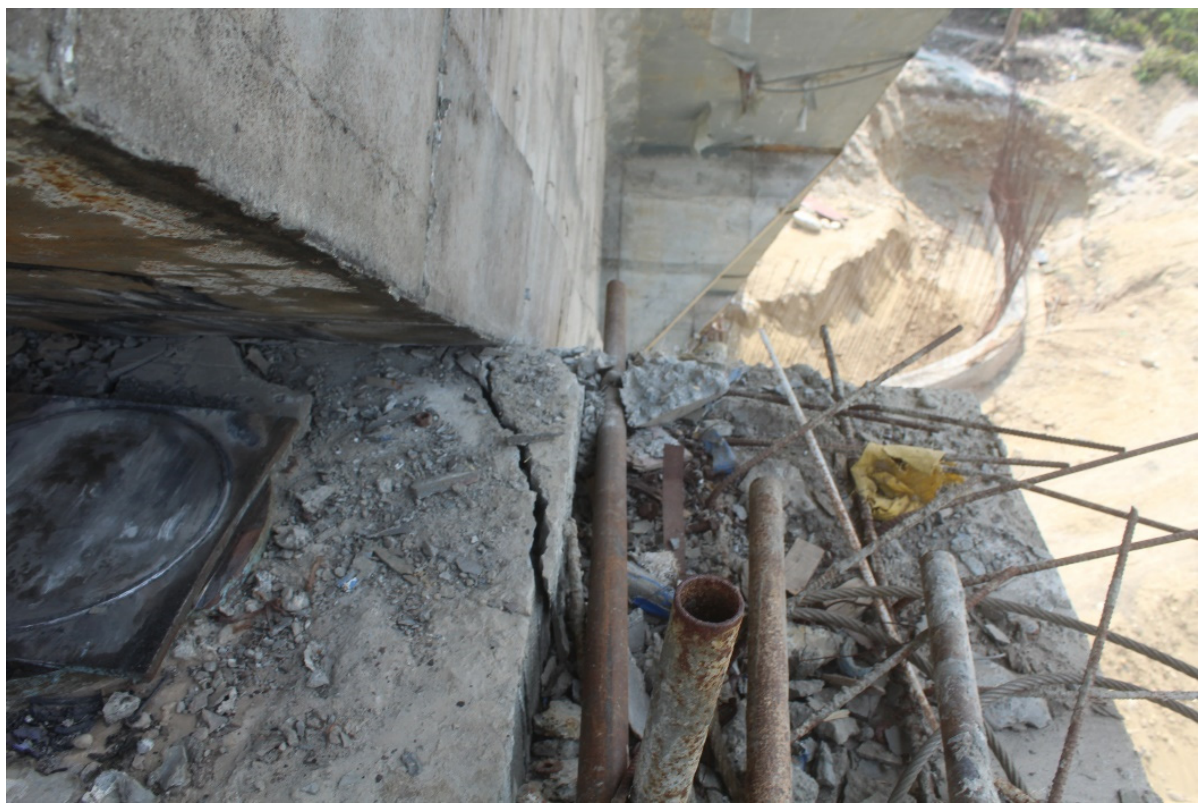

Figure 19. Damage to pier cap of Pier-1 due to Span-1 collapse.

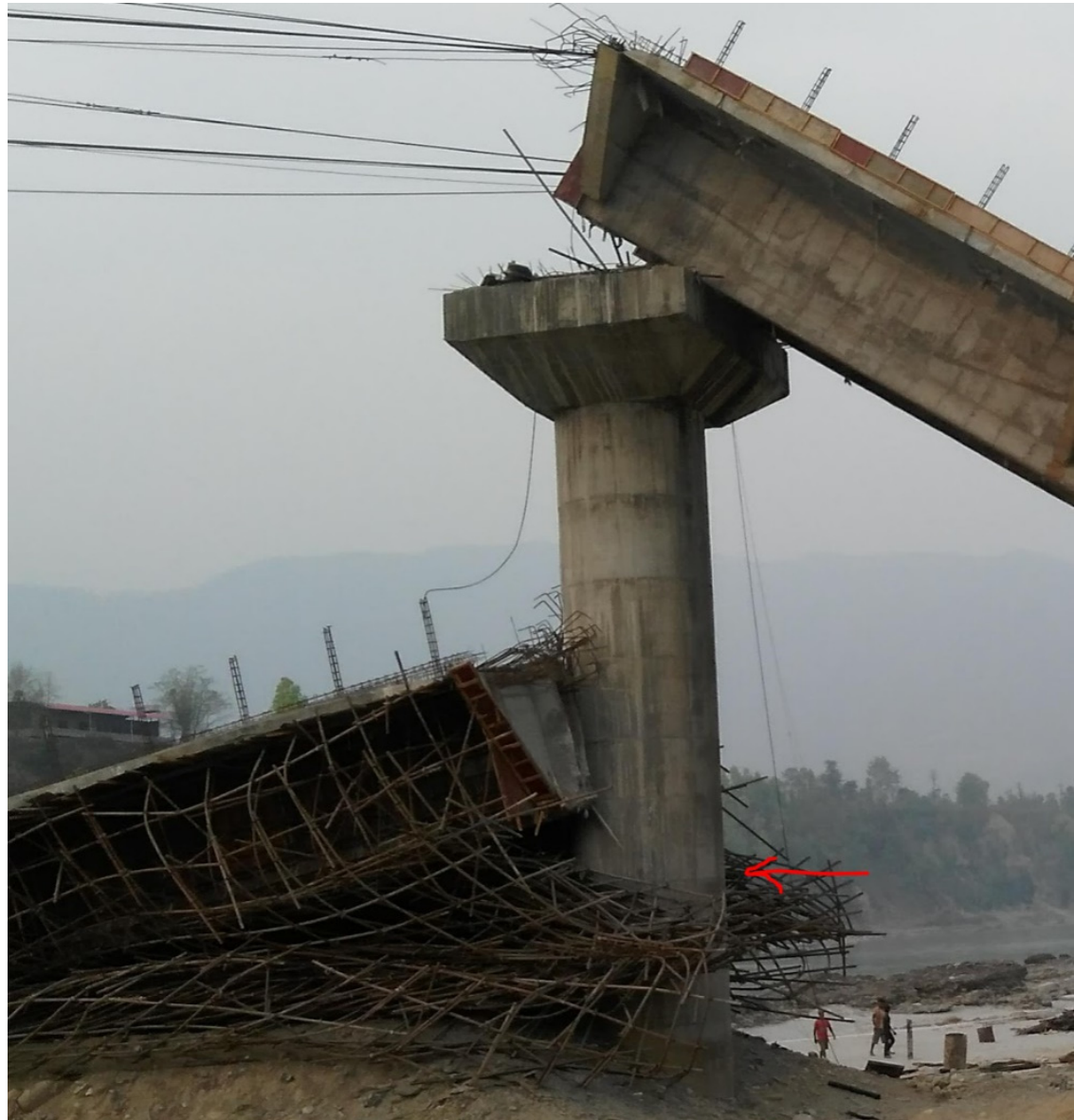

Figure 20. Pier-1 being pushed by Span-1 from the top and Span-2 from the middle in opposite directions. Horizontal crack is marked with an arrow. 


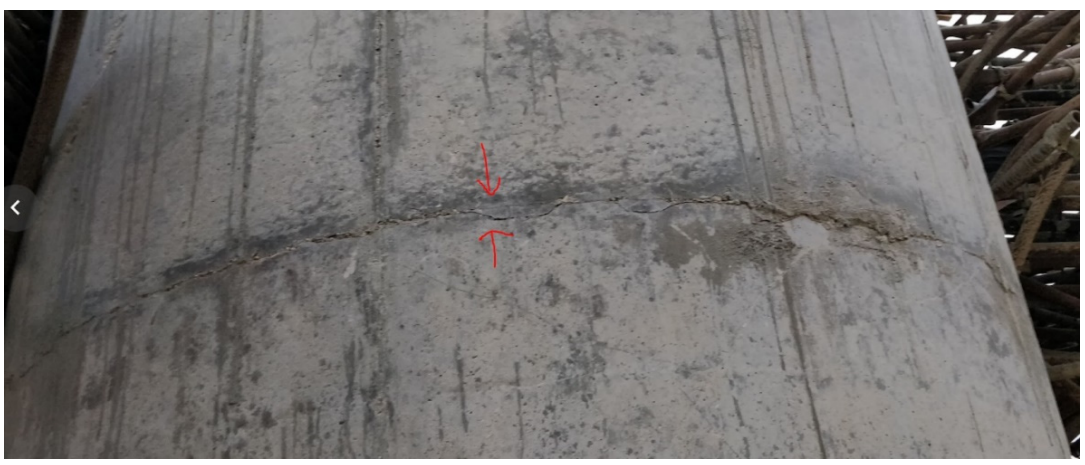

Figure 21. Horizontal crack towards the Span-1 side of Pier-1, at $2.5 \mathrm{~m}$ height from the ground level.

\subsection{Damage to Formwork and Falsework}

All the falseworks (props) under Span-2 were collapsed. The props were buckled outwards across the span (Figure 22), with inclination mostly towards the left bank (Chitwan side). Most of the steel formworks were intact, even after the collapse of the beam (Figure 23). However, near the fracture zone of the deck, the formworks were distorted due to bearing failure at bolted locations.

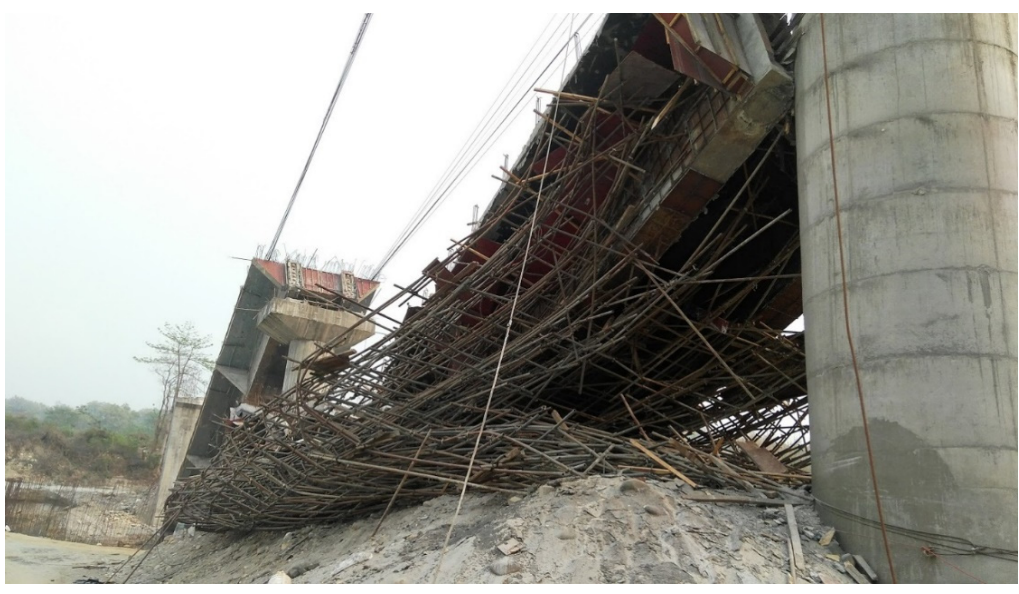

Figure 22. Falsework damage in Span-2; buckling was mostly towards upstream side, indicating damage initiation by settlement of downstream side first.

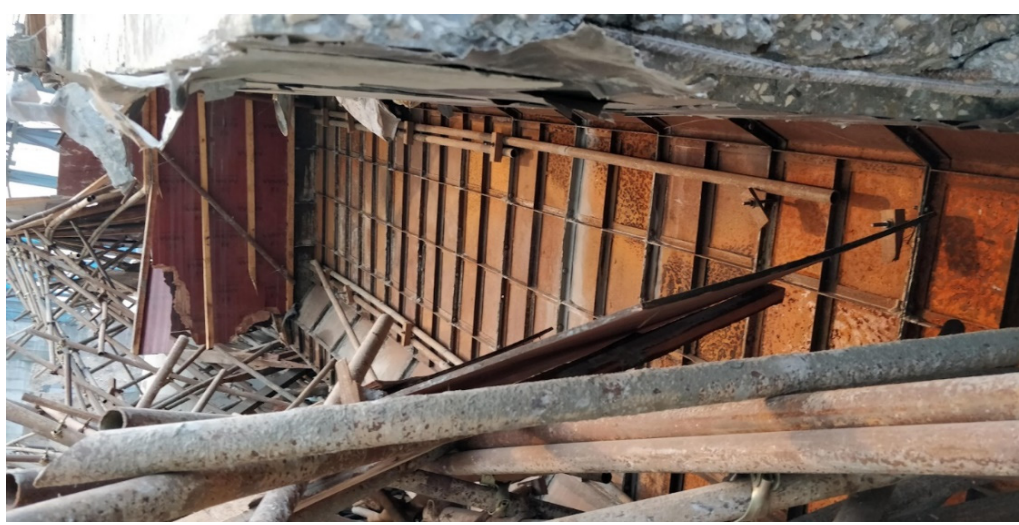

Figure 23. Intact formwork on other part of Span-2 (except the beam fracture location), indicating failure mechanism consists only one failure location.

\subsection{Other Damages}

Some other damage mechanisms were observed at the ends of the fourth span above Abutment-2 (Figure 24). The edge around the prestressing cable anchorage was found to 
be cracked (Figure 25). The pier caps were also damaged in Pier-2 and Pier-3 due to the exertion of tensile force by the steel towers. Furthermore, the RC pedestal over the pier cap of Pier-3 was heavily damaged, as shown in Figure 26. Similarly, damage to the RC pedestal over the pier cap of Pier-2 is shown in Figure 27.

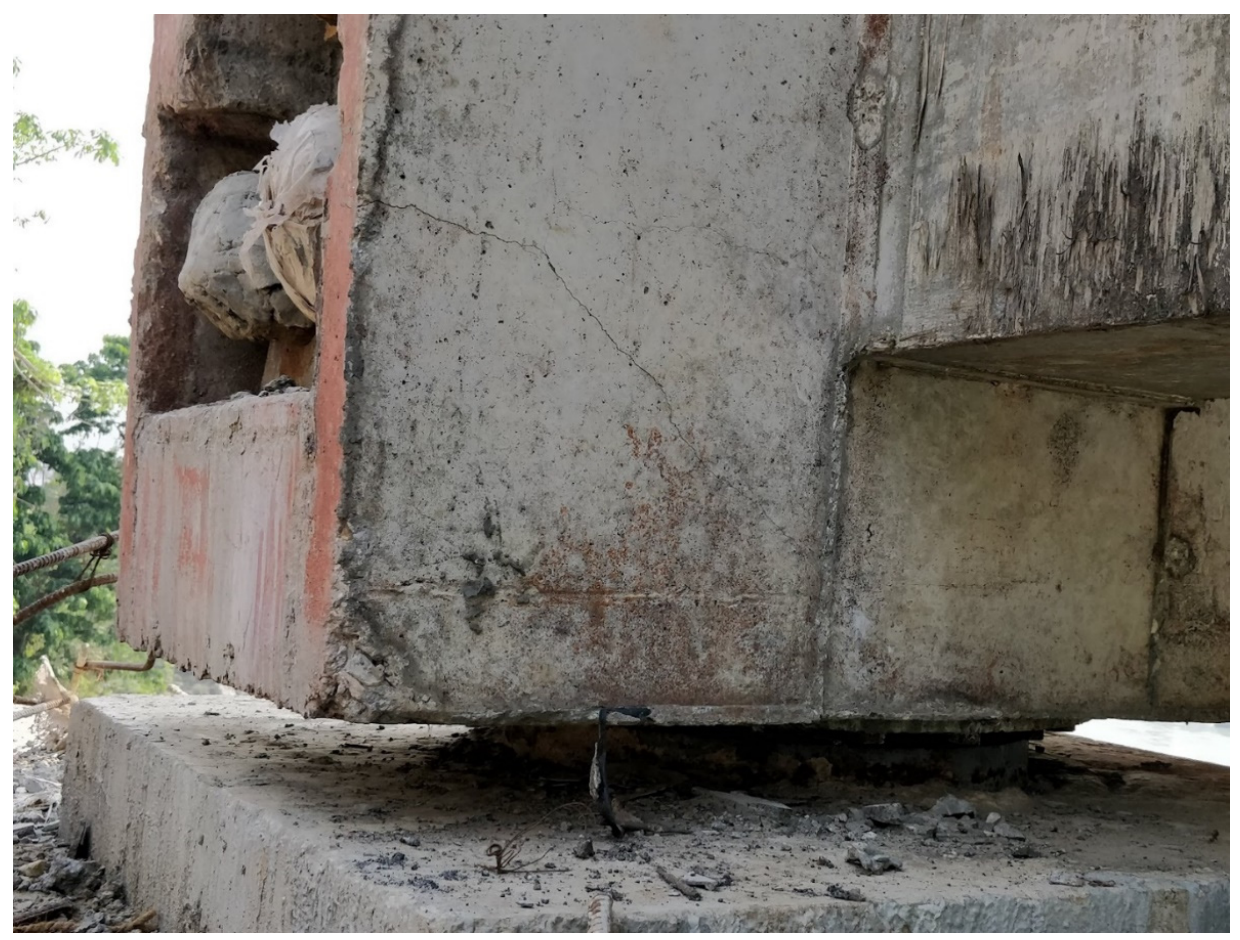

Figure 24. Some cracks around the end of Span-4 lower prestressing cable anchor zone, on Abutment2 side.

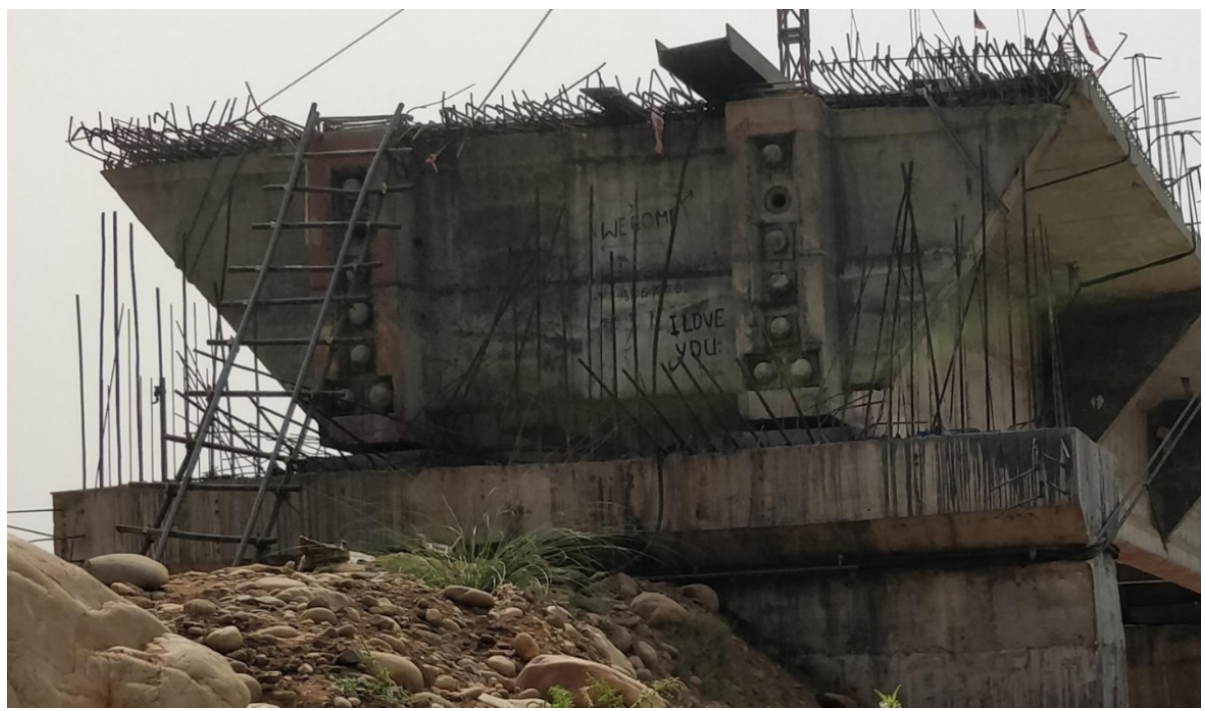

Figure 25. End of Span-4 over Abutment-2. Some temporary suspension cables were anchored at abutment and others were anchored near the end of Span-4 deck. 


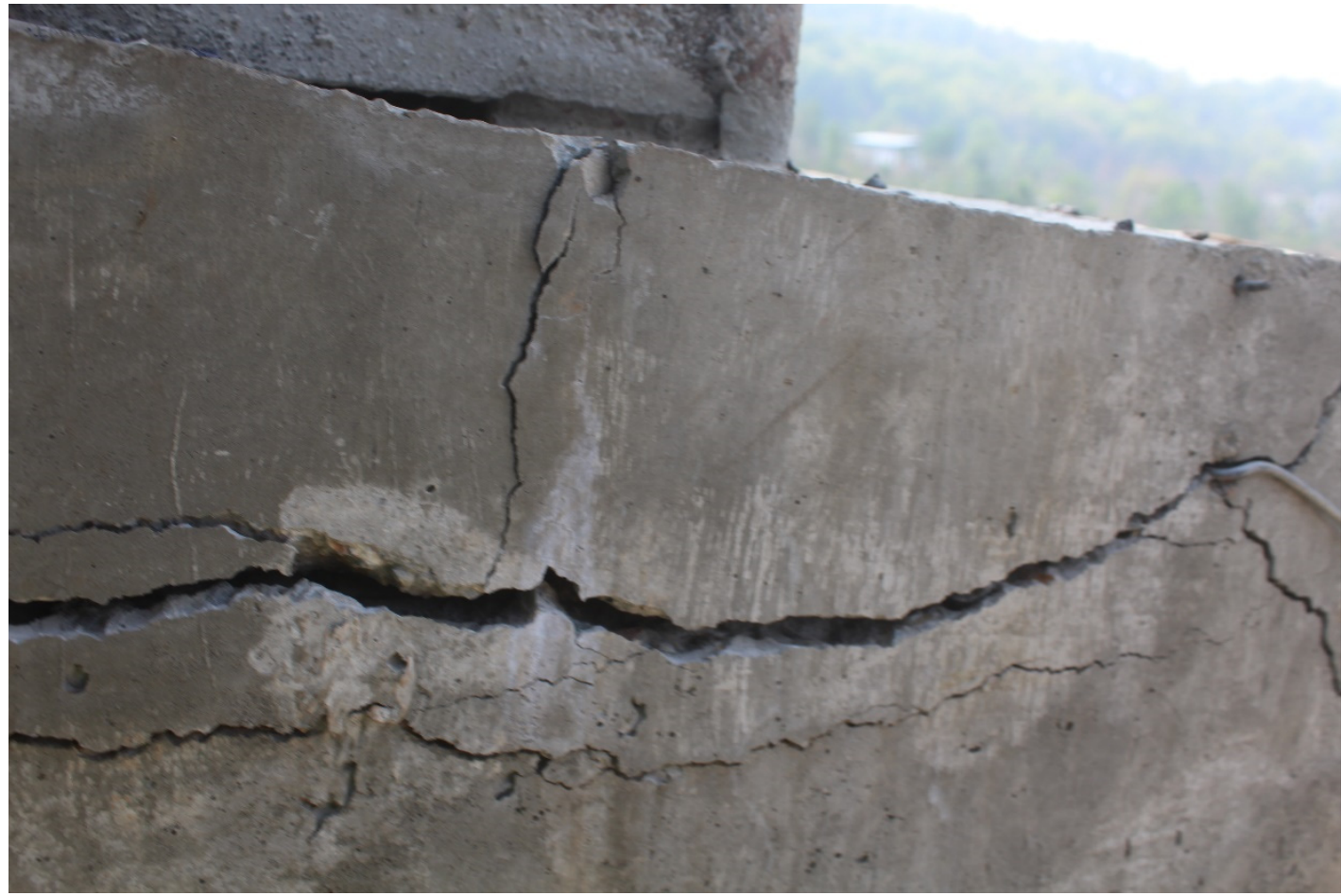

Figure 26. Heavily damaged pier cap above Pier-2 due to the tensile action exerted by the temporary suspension cables on the steel towers.
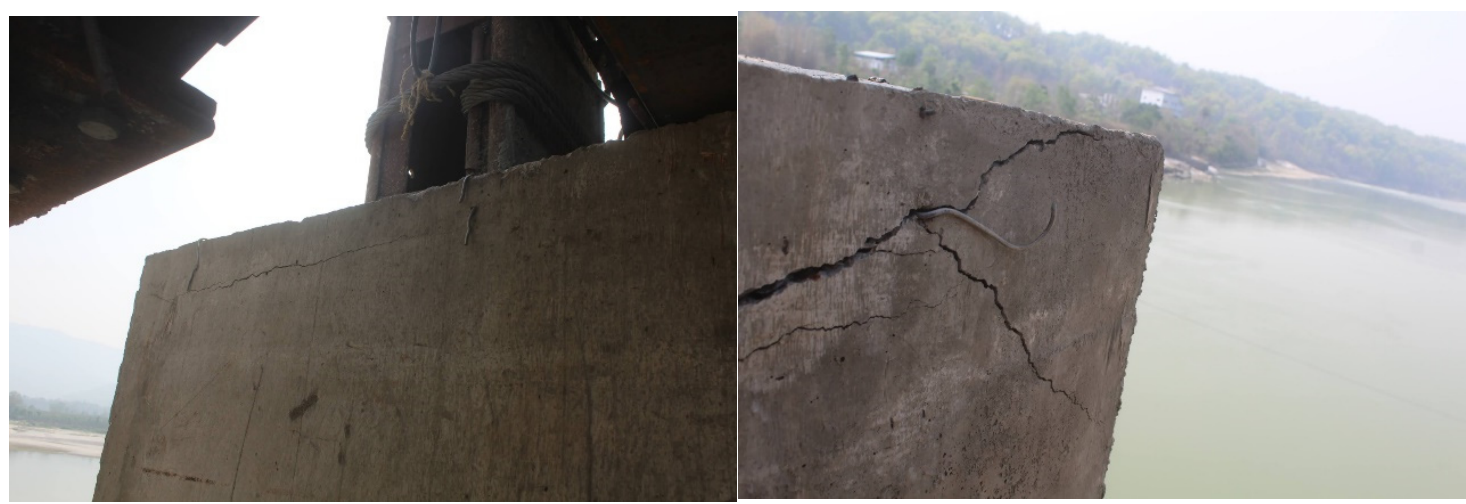

Figure 27. Damage to the RCC pedestal over pier-cap of Pier-2; steel tower was erected over it as a temporary structure for prestressing.

\section{The Failure Sequence}

The failure mechanism is identified based on the nature of observed damage, geometry, member orientation, and the type of damage. The properties and mechanisms represented herein reflect the characteristics of the concreting after 38 days of casting. The failure mechanism is chronologically presented as follows:

a. There was a gradual settlement of falsework supporting the steel league of Span2 on the downstream side (Figure 28). The settlement was caused by a gradual displacement of loose sand that was piled up to downscale the height of the falsework. The main hypothesis was that the collapse occurred as the rate of settlement had increased once curing was stopped five days prior to the collapse. This may be due to the fact that the water content was lost from the loose soil. In addition, small triggers, such as the vibration from the generator operating beside the embankment used by the steel erection team, as well as human movements, may have caused a significant displacement of loose sand; 
b. The settlement of the falsework induced a high bending moment on the to-beprestressed concrete deck of Span-2. It was even greater towards the downstream side where the settlement was also larger;

c. After about $250 \mathrm{~mm}$ of settlement (measured in situ during reconnaissance), the longitudinal rebars of the downstream-side beam fractured, and progressively, there was high bending on slab rebars, causing several flexural cracks near the beamfracture location;

d. There was a second settlement of $300 \mathrm{~mm}$ that caused an instability of the edge props and the redistribution of force to the falsework and the deck at the upstream side. Consequently, the upstream props buckled, causing the flexure failure of the upstream-side beam together with a sudden weakening of the whole section, and ultimately the collapse of the whole deck;

e. During the collapse process of Span-2, Pier-1 was pushed towards Abutment-1. Pier2 was pushed towards the Pier-3 side, causing a rapid increase of tensile force in the cables anchored to the Span-1 deck that were used to support the steel span during the erection process. This force caused the horizontal sliding of Span-1 towards Pier-1, causing both the failure of the bearings and the detachment of Abutment-1. The sliding left several bearing marks on the soffit of the beam. It started because the tension on the cable increased and caused the failure of the hinge bearing over Abutment-1. Then, due to the residual tension in the cable, and due to the lack of proper anchorage, sliding continued;

f. Hinging over Pier-1, the Abutment-1 side of the deck fell off with a rotational motion and subsequently hit the ground with a large impact force;

g. The failure of Span-2 was initiated first, but the falling was relatively gradual, as depicted by the friction and scouring impressions on both piers. After the Span-2 collapse was initiated, the displacement (and subsequent collapse) of Span-1 was triggered. Moreover, Span-1 fell rapidly. Some cables stretched, and concrete scouring noises were heard by the laborers stationed at the construction site;

h. During the collapse of Span-1, the tensions developed against the pull by Span-1 caused significant damage to RC pedestals over the pier caps of Pier-1 and Pier-2 that were used to support temporary steel towers.

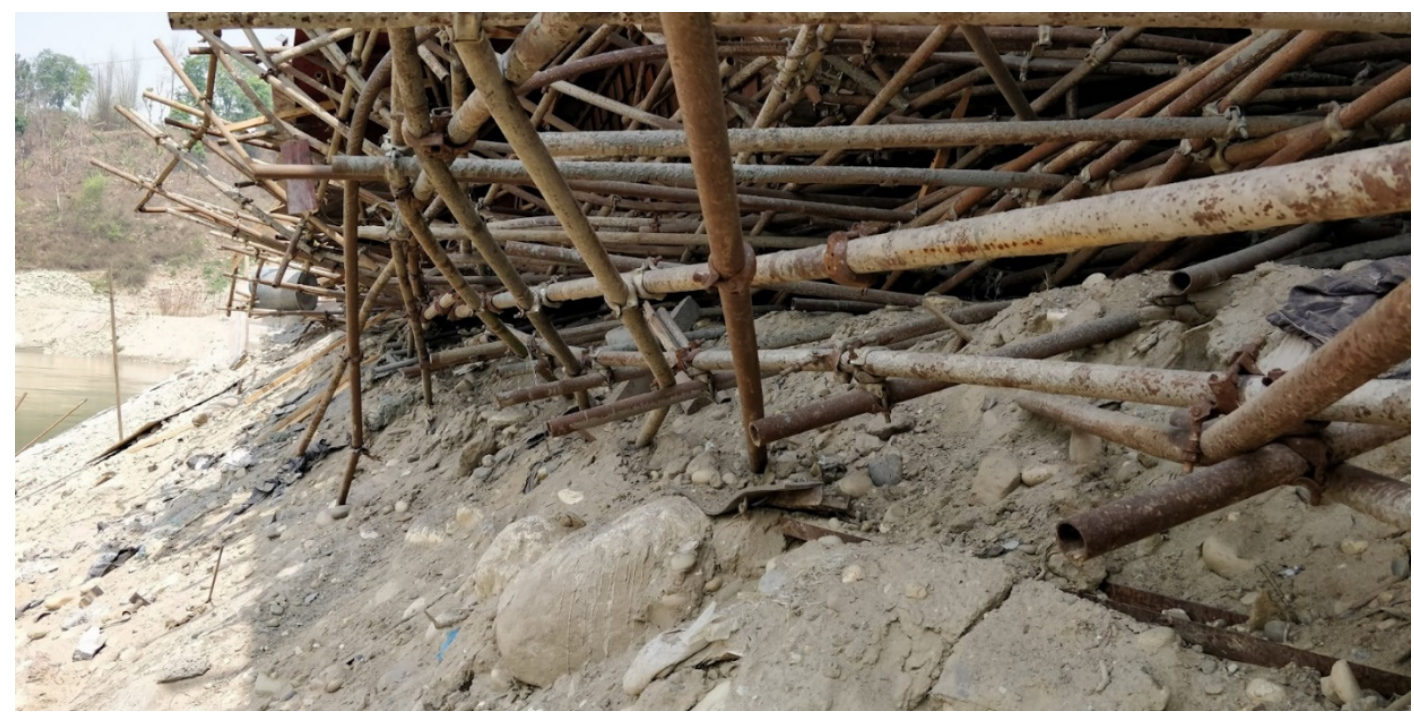

Figure 28. Settlement of downstream-most steel-section league-supporting falseworks.

\section{Numerical Simulations}

In order to capture the mechanisms developed in Span-2, a three-dimensional (3D) numerical model (Figure 29) of the bridge was created in SAP-2000 v.23 [22]. The bridge 
was modeled with linear elastic materials using HYSD-Fe500 rebars and M45 concrete. In total, 535 nodes, 191 shell elements, and 272 frames were created during finite element analysis. The deck was considered as a unique section with homogeneous properties, with a cross-sectional area of $10.78 \mathrm{~m}^{2}$, transversal inertia of $5.38 \mathrm{~m}^{4}$, and vertical inertia of $75.9 \mathrm{~m}^{4}$. The bridge was restrained with hinges in order to ensure the equilibrium of the entire system under the vertical and horizontal loads. Under the entire bridge span, vertical elements of 2" diameter and a steel section of a partial length of $500 \mathrm{~mm}$ at a longitudinal spacing of $300 \mathrm{~mm}$ were deployed to simulate the temporary supports as observed in the field. The hinges were embedded in the elements in order to introduce more degrees of freedom in the model, which improve convergence when multiple hinges fail at the same time. In addition, stiffness-proportional damping was considered in the analyses (dead, modal, and linear elastic). In particular, the mass and self-weight loads were applied on the shell elements as uniformly distributed load intensities over the plane of the element. The magnitude of the self-weight is equal to the weight density multiplied by the shell thickness. Different ground displacements were provided in the falsework joints, ranging from $10 \mathrm{~mm}$ to $300 \mathrm{~mm}$, and tensile stress was checked for corresponding displacement values. Initially, the props were carrying the dead load properly, with approximately $59 \mathrm{KN} / \mathrm{m}$ of reaction under each of the two main beams. As the settlement gradually increased, the reaction of the props towards the ends decreased, while the reaction on props towards the center increased. At $10.75 \mathrm{~mm}$ central deflection of the beam, due to the settlement of prop support, 3.4 MPa of tensile stress is induced at the bottom of the beam. The bearing prop reaction near the center is increased to $117 \mathrm{KN} / \mathrm{m}$. At $20.6 \mathrm{~mm}$ central deflection of the beam due to the settlement of prop support, $7.53 \mathrm{MPa}$ of tensile stress is induced at the bottom of the beam. However, if the beam is not cracked, the prop reaction near the center again decreases to $94 \mathrm{KN} / \mathrm{m}$. Further settlement analysis reveals that there would be a maximum of $29.46 \mathrm{~mm}$ deflection of the beam with a maximum tensile stress of $11.49 \mathrm{MPa}$ at the bottom of the beam. However, this stage was never achieved due to the early tensile rupture of the beam. The flexural crack must have initiated at about 15 to $20 \mathrm{~mm}$ of central deflection, after which the moment of resistance of the section dropped to near zero and the collapse of the span occurred. It is observed that Span-2 would fail in tension even at $50 \mathrm{~mm}$ prop displacement, which is fairly lower than the displacement observed in the field $(250 \mathrm{~mm})$. Figures 30 and 31, respectively, represent the distributions of tensile stresses for $50 \mathrm{~mm}$ and $10 \mathrm{~mm}$ settlement scenarios. The tensile capacity for M45 grade concrete is expected to be much lower than the tensile stresses that can occur in the failure regions. The finite element models effectively captured the main failure locations observed in the field, as shown in Figures 30 and 31.

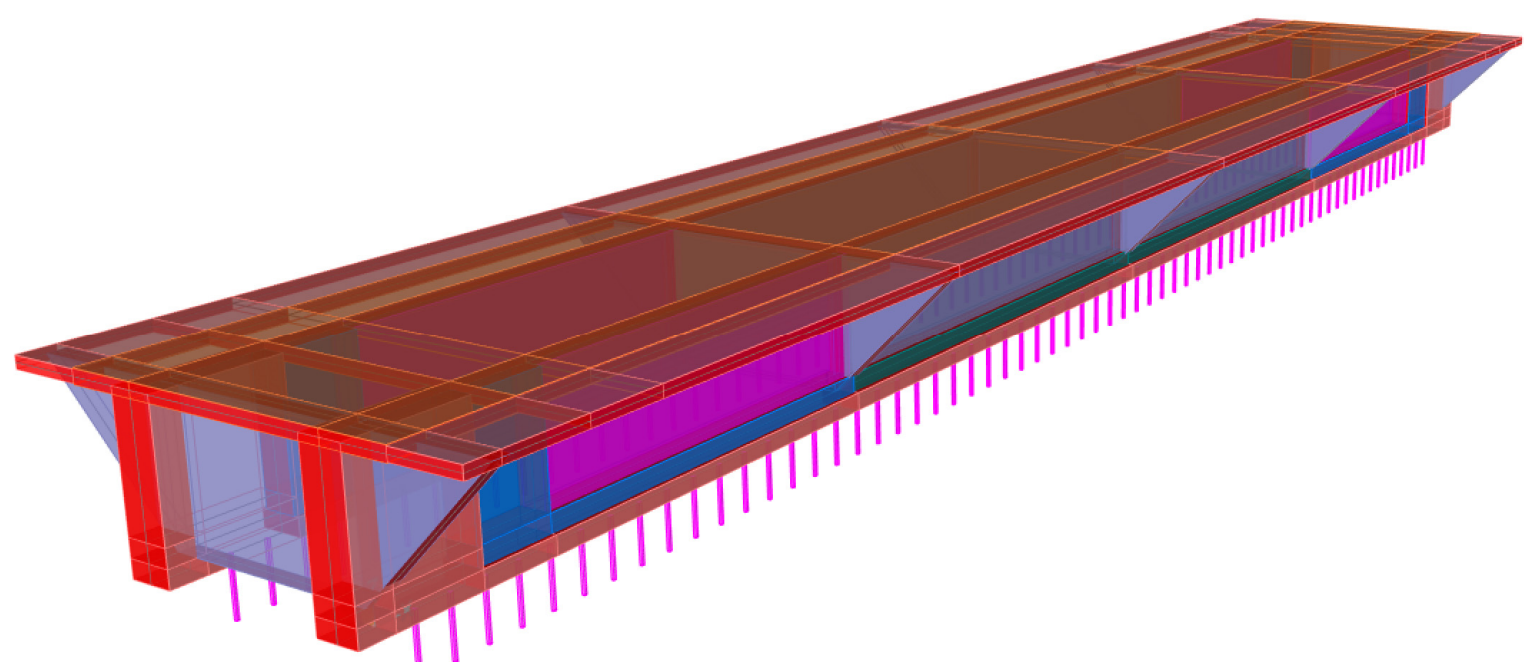

Figure 29. 3D representation of bridge Span-2 in FE model. 

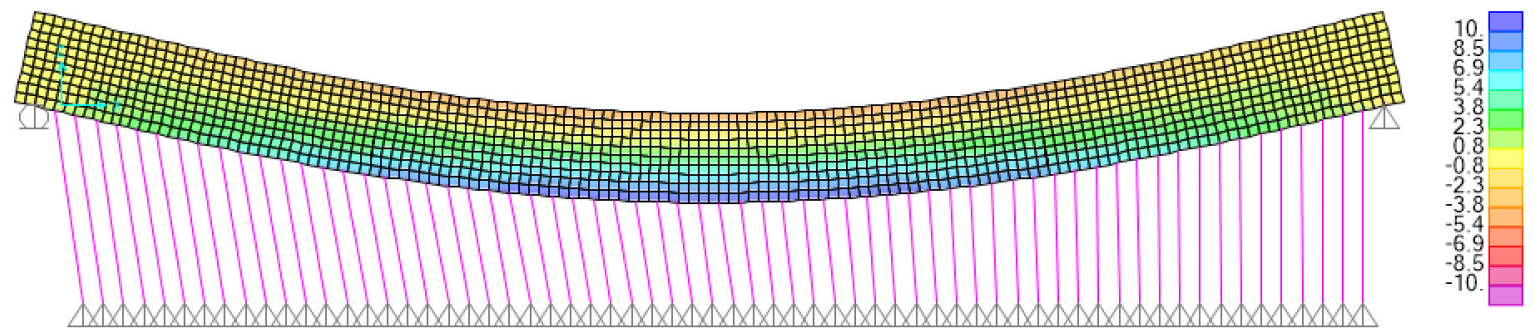

Figure 30. Tensile stress distribution in Span-2 for $50 \mathrm{~mm}$-settlement scenario.
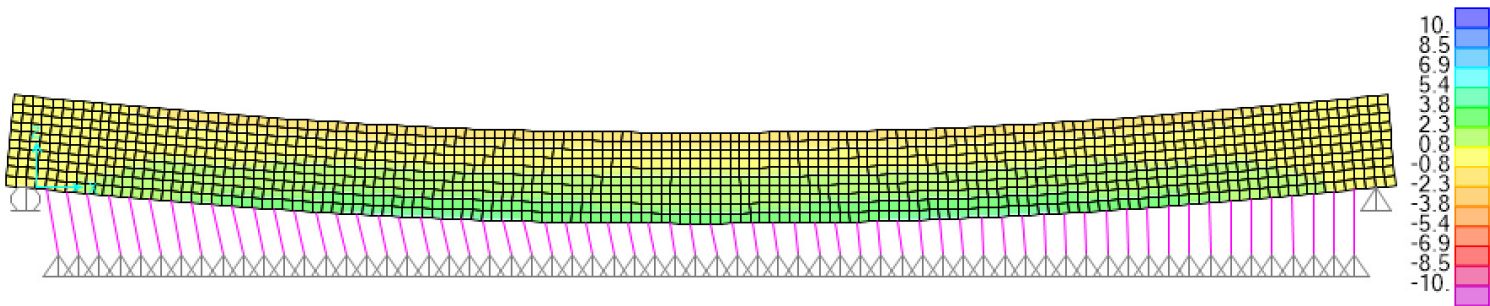

Figure 31. Tensile stress distribution for $10 \mathrm{~mm}$-settlement scenario.

\section{Discussion}

Catastrophic failures are commonly rooted for several reasons, especially in structural engineering, and cannot be explained by a unique factor. Considering uncertainties in the various stages of planning, design, and implementation, different levels of safety factors are incorporated into the design. Some degree of weakness in different stages normally does not result in major failures. However, sometimes, the weakness occurs in such a critical combination that their effects are integrated, and catastrophic failure of the structure becomes inevitable.

For the failure of the Thimura bridge, there could have been several factors that aggravated the effects, simultaneously leading to the collapse of Span-1 and Span-2. The embankment established to support the falseworks (props) consisted of local riverbank material. The riverbank material was poorly graded cohesionless sand with little gravel. Precisely, the sand consists of a common typology of riverbank material that is commonly found in Nepal, with a varied granulometric distribution of grains from fine silts to gravel. When not supported from the sides, such dry materials reflect very poor bearing capacity, especially near the edge of embankments. Thus, the falsework would easily settle down due to the displacement of loose sand. For loose and dry embankment materials used at the site to support the falsework, vibrations may induce significant reductions of the shear resistance, causing the sliding of material, especially where loosely piled up materials exist, as in the case of Thimura bridge site. The continuous use of the generator for site works could have contributed in the gradual weakening of the embankment, which gradually settled under the load of the deck right below the formwork. The earthquake-induced vibration that occurred a few days earlier could have also aggravated the settlement.

It is customary in Nepal to prepare the scaffolding (temporary structures/props supporting the concrete formwork) by filling the embankment up to a certain height and raising steel scaffolding above it. The steel scaffolding was between 10 and $13 \mathrm{~m}$ in height between the bridge deck soffit and the top of embankment. The props were placed at $0.6 \mathrm{~m}$ center to center under the girder to $1 \mathrm{~m}$ center to center under the slab. Vertical props were tied at $1.5 \mathrm{~m}$ center to center using horizontal props. Most importantly, the top width of the soil embankment was not much wider than the bridge deck width, and thus, it did not guarantee a proper placement of the steel-league support. The erection of the steel span was performed with steel towers and cables, which were anchored to the bridge deck, for which the deck was not designed. Furthermore, there was neither any documented design for the tower nor any tension measuring device for the anchor cables from the steel towers. The falseworks for the concrete span were provided over 
the soil embankment without proper confinement, which is not a recommended practice. Furthermore, no surface stabilization, such as plain cement concreting (PCC), was found over the surface, except a very thin layer of cement grout at some locations that caused moisture variation and marred the stability of the embankment material. No longitudinal stoppers were observed in the design that would resist the excessive displacement of the bridge deck under unforeseen loads. Furthermore, no design was found for the temporary suspension cable and its anchorage, indicating that proper design was not carried out. The designed reinforcement on the beam was found to be too low to contribute any significant strength to the girder. If there would have been some more reinforcement to resist some portions of the load through reinforced concrete beam action, the failure could have been less severe. For the erection method used-using steel towers and cables to temporarily hang the steel sections of steel span-the continuous movement of the live load and wind caused a continuous vibration on the partially connected steel deck, causing cyclic loads on the cables. The cables then induced cyclic loading to the deck, especially in Span-1. This eventually caused the weakening of the hinge bearing over Abutment-1, resulting in the sliding of Span-1. The concrete compressive strength test results were reported to be within the permissible ranges. However, a rebound hammer test on the concrete showed results lower than the expected values. This could have also aggravated the damage scenario, even at less settlement or unfavorable conditions.

\section{Conclusions}

Currently, prestressed bridges are common because of the reduced construction time; however, there are a number of cases in which prestressed bridges have collapsed during construction. Using a forensic approach, we present a case study of an under-construction bridge collapse in this paper. We performed field investigation, in situ testing, and finite element analysis to determine the causes and consequences of the bridge collapse. Although rapid construction is possible in the case of prestressed construction, the effective placement of falseworks is necessary to prevent under-construction collapse mechanisms. Furthermore, falseworks should be designed to account for the possible settlements due to static loads from the superstructure, as well as to counteract the possible embankment settlement. The erection towers can be also problematic if the mechanisms they possess are not accounted for while prestressing. As observed in situ and as confirmed by the finite element analysis, the collapse of the falseworks caused the collapse of two spans of the Thimura bridge. The prestressing arrangement was responsible for the collapse of Span-1, which would have been preventable if cables were arranged properly. The findings presented in this paper will be insightful to prevent future incidents, as bridge collapse is usually governed by more than one factor, and those considered as marginal factors can also lead to grave consequences. The failure mechanisms documented in this study can also provide insights for future designs and constructions. Future studies can conduct more detailed and destructive field tests so as to collect realistic modeling parameters from the field and replicate the same in finite element models. Such results will be more insightful to explain complex failure mechanisms.

Author Contributions: Conceptualization, R.A. and D.G.; methodology, R.A., D.G. and P.J.; software, R.A., P.J. and L.B.; validation, R.A., D.G. and D.F.; formal analysis, R.A., P.J. and L.B.; investigation, R.A., P.J., L.B., D.T. and D.G.; resources, D.F.; data curation, R.A., D.G. and D.T.; writing-original draft preparation, R.A. and D.G.; writing-review and editing, P.J., L.B., D.T. and D.F.; visualization, R.A.; supervision, R.A. and D.G.; project administration, R.A.; funding acquisition, D.G. All authors have read and agreed to the published version of the manuscript.

Funding: This research received no external funding.

Acknowledgments: The authors acknowledge the field reconnaissance support provided by the Nepal Engineers' Association. In particular, Triratna Bajracharya is thanked for his proactive project initiation immediately after the incident. The authors thank Krishna Raj Adhikari, Shiva Chapagain, Bijay Darai, Subash Pokharel, and Upendra Subedi for their support during the field work. 
Conflicts of Interest: The authors declare no conflict of interest.

\section{References}

1. Cao, R.; El-Tawil, S.; Agrawal, A.K. Miami Pedestrian Bridge Collapse: Computational Forensic Analysis. J. Bridge Eng. 2020, 25, 04019134. [CrossRef]

2. Tremblay, R.; Mitchell, D. Collapse during Construction of a Precast Girder Bridge. J. Perform. Constr. Facil. 2006, 20, 113-125. [CrossRef]

3. Lewis, P.M.R.; Reynolds, K. Forensic Engineering: A Reappraisal of the Tay Bridge Disaster. Interdiscip. Sci. Rev. 2002, 27, 287-298. [CrossRef]

4. Peng, W.; Tang, Z.; Wang, D.; Cao, X.; Dai, F.; Taciroglu, E. A Forensic Investigation of the Xiaoshan Ramp Bridge Collapse. Eng. Struct. 2020, 224, 111203. [CrossRef]

5. Gautam, D.; Rupakhety, R. Empirical seismic vulnerability analysis of infrastructure systems in Nepal. Bull. Earthq. Eng. 2021, 19, 6113-6127. [CrossRef]

6. Scattarreggia, N.; Salomone, R.; Moratti, M.; Malomo, D.; Pinho, R.; Calvi, G.M. Collapse Analysis of the Multi-Span Reinforced Concrete Arch Bridge of Caprigliola, Italy. Eng. Struct. 2022, 251, 113375. [CrossRef]

7. Clemente, P. Monitoring and Evaluation of Bridges: Lessons from the Polcevera Viaduct Collapse in Italy. J. Civ. Struct. Health Monit. 2020, 10, 177-182. [CrossRef]

8. Jiang, L.; Ye, J.; Zheng, H. Collapse Mechanism Analysis of the FIU Pedestrian Bridge Based on the Improved Structural Vulnerability Theory (ISVT). Eng. Fail. Anal. 2019, 104, 1064-1075. [CrossRef]

9. Meng, Q.; Zhu, J.; Wang, T. Numerical prediction of long term deformation for prestressed concrete bridges under random heavy traffic loads. J. Bridge Eng. 2019, 24, 04019107. [CrossRef]

10. Yang, J.; Guo, T.; Li, A. Experimental investigation on long-term behavior of prestressed concrete beams under coupled effect of sustained load and corrosion. Adv. Struct. Eng. 2020, 23, 2587-2596. [CrossRef]

11. Bonopera, M.; Chang, K.C. Novel method for identifying residual prestress force in simply supported concrete girder-bridges. Adv. Struct. Eng. 2021, 24, 3238-3251. [CrossRef]

12. Gautam, D.; Rupakhety, R.; Adhikari, R.; Baruwal, R.; Pokhrel, S.; Aryal, S. System identification of typical pre-code highway bridge in operation using heavy vehicle excitations. In Proceedings of the 17th World Conference on Earthquake Engineering, Sendai, Japan, 13-18 September 2020.

13. Li, Y.; Dong, Y.; Frangopol, D.M.; Gautam, D. Long-term resilience and loss assessment of highway bridges under multiple natural hazards. Struct. Infrastruct. Eng. 2020, 16, 626-641. [CrossRef]

14. Gautam, D. On seismic vulnerability of highway bridges in Nepal: 1988 Udaypur earthquake ( $\mathrm{M}_{\mathrm{W}}$ 6.8) revisited. Soil Dyn. Earthq. Eng. 2017, 99, 168-171. [CrossRef]

15. Gautam, D.; Rupakhety, R.; Adhikari, R. Empirical fragility functions for Nepali highway bridges affected by the 2015 Gorkha earthquake. Soil Dyn. Earthq. Eng. 2019, 126, 105778. [CrossRef]

16. Thapa, S.; Shrestha, Y.; Gautam, D. Seismic fragility analysis of RC bridges in high seismic regions under horizontal and simultaneous horizontal and vertical excitations. Structures 2022, 37, 284-294. [CrossRef]

17. Forcellini, D. A new methodology to assess indirect losses in bridges subjected to multiple hazards. Innov. Infrastruct. Solut. 2019, 4, 10. [CrossRef]

18. Forcellini, D. Resilience-based methodology to assess soil structure interaction on a benchmark bridge. Infrastructures 2020, 5, 90. [CrossRef]

19. Forcellini, D.; Walsh, K.Q. Seismic resilience for recovery investments of bridges methodology. In Proceedings of the Institution of Civil Engineers_-Bridge Engineering; Thomas Telford Ltd.: London, UK, 2021. [CrossRef]

20. Forcellini, D. Fragility assessment of seismic isolated bridges with soil-structure interaction effects. In Proceedings of the Institution of Civil Engineers-Bridge Engineering; Thomas Telford Ltd.: London, UK, 2021. [CrossRef]

21. Tsiavos, A.; Amrein, P.; Bender, N.; Stojadinovic, B. Compliance-based estimation of seismic collapse risk of an existing reinforced concrete frame building. Bull. Earthq. Eng. 2021, 19, 6027-6048. [CrossRef]

22. Computers and Structures Inc. SAP 2000; CSI Inc.: Pomona, CA, USA, 2013. 